\title{
Development of a Process-Based Littoral Sediment Transport Model for Dauphin Island, Alabama
}

By Robert L. Jenkins III, Joseph W. Long, P. Soupy Dalyander, David M. Thompson, and Rangley C. Mickey

Open-File Report 2020-1011

U.S. Department of the Interior

U.S. Geological Survey 


\title{
U.S. Department of the Interior \\ DAVID BERNHARDT, Secretary
}

\author{
U.S. Geological Survey \\ James F. Reilly II, Director
}

U.S. Geological Survey, Reston, Virginia: 2020

For more information on the USGS-the Federal source for science about the Earth, its natural and living resources, natural hazards, and the environment-visit https://www.usgs.gov/ or call 1-888-ASK-USGS (1-888-275-8747).

For an overview of USGS information products, including maps, imagery, and publications, visit https://www.usgs.gov/pubprod/.

Any use of trade, firm, or product names is for descriptive purposes only and does not imply endorsement by the U.S. Government.

Although this information product, for the most part, is in the public domain, it also may contain copyrighted materials as noted in the text. Permission to reproduce copyrighted items must be secured from the copyright owner.

Suggested citation:

Jenkins, R.L., III, Long, J.W., Dalyander, P.S., Thompson, D.M., and Mickey, R.C., 2020, Development of a process-based littoral sediment transport model for Dauphin Island, Alabama: U.S. Geological Survey Open-File Report 2020-1011, 43 p., https://doi.org/10.3133/ofr20201011. 


\section{Acknowledgments}

The authors would like to give special thanks to our partners in U.S. Army Corps of Engineers for providing the observational data for comparison to model output. Thanks also goes to the entire Delft-3D team at Deltares, many of whom provided vital input on morphology parameterization. The authors specifically thank Timothy Nelson and Alfredo Aretxabaleta for reviewing this report. 


\section{Contents}

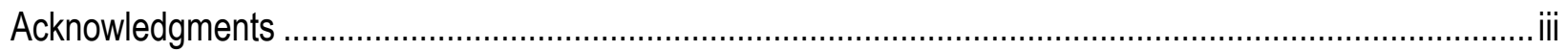

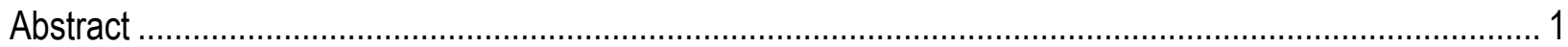

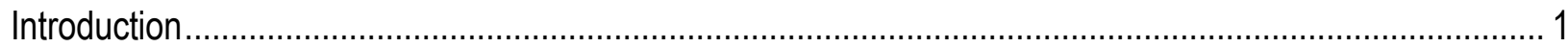

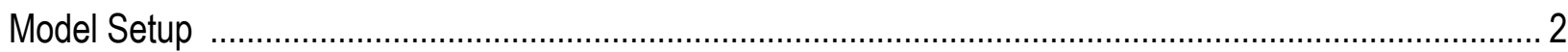

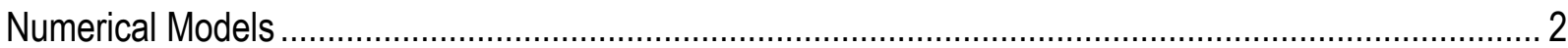

Hydrodynamic and Sediment Transport Model ...................................................................... 2

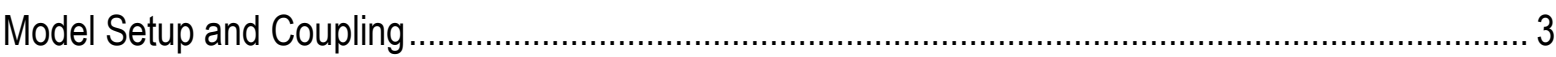

Topobathymetric Data and Digital Elevation Models .............................................................. 6

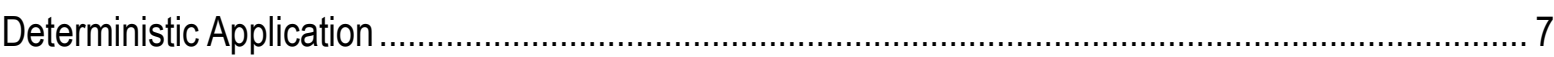

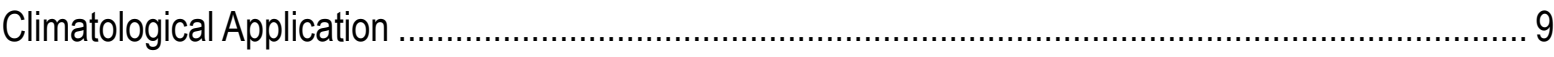

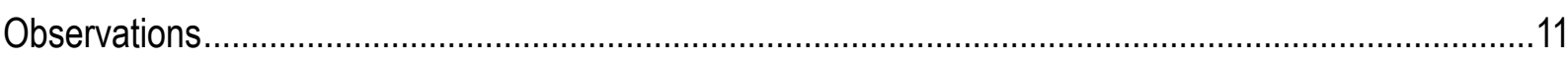

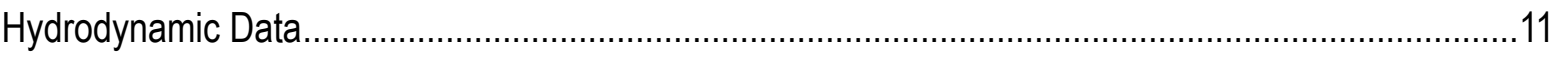

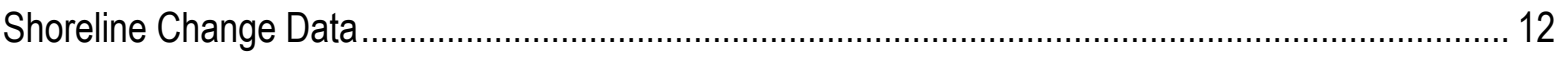

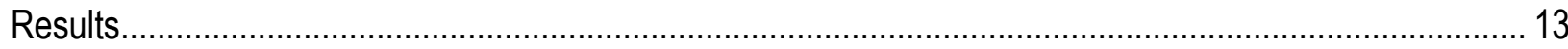

Comparison to Observations_Deterministic Simulations ................................................................... 13

Acoustic-Doppler Current Profile Comparison ................................................................................... 13

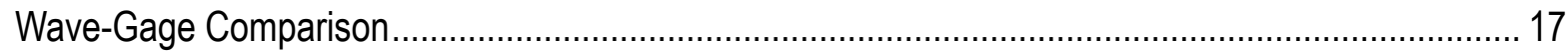

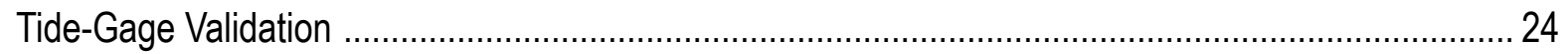

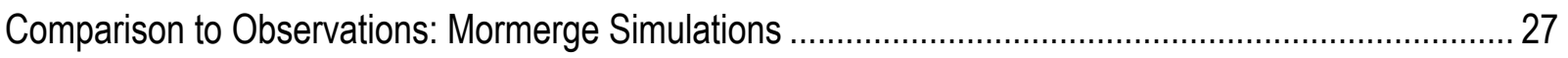

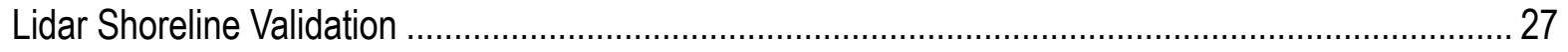

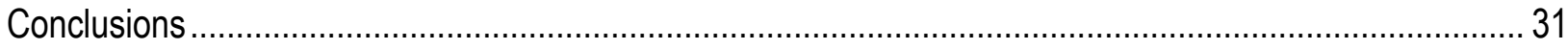

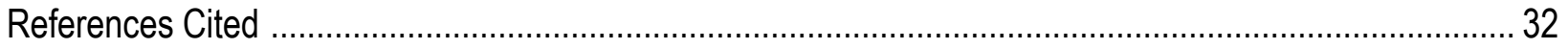

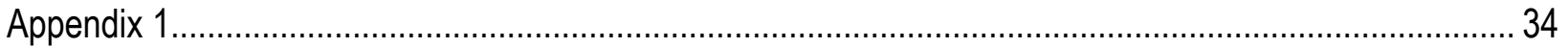

\section{Figures}

1. Flow chart in which $S_{1}, S_{2}, \ldots S_{n}$ represent hydrodynamic forcing conditions at various simulation

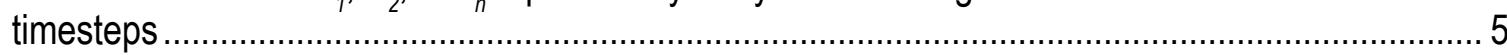

2. Map showing the study area and digital elevation model for this report...................................... 6

3. Colored map of the digital elevation model for this model showing observation locations within the study area.

4. Graphs showing water-level observations and Hybrid Coordinated Ocean Model data at Dauphin Island, Alabama for a 6-month period

5. Scatter plots of $A$, trip 1 and trip 2 modeled versus observed through-channel velocity in Mobile Bay Inlet. $B$, trip 1 and trip 2 modeled versus observed V-velocity in Mobile Bay Inlet........ 
6. Graphs showing comparisons between observed depth and model digital elevation model depths on all acoustic Doppler current profiler transects during trip 1 and trip 2

7. Time series graphs showing observed and modeled wave variables at the Aquadopp wave gage

8. Time series graphs showing observed and modeled wave variables at the acoustic wave and current sensor wave gage.

9. Graphs showing a comparison between WaveWatch III wind and wave height forcing and observed winds and wave heights at National Data Buoy Center 42012 2..................................... 24

10. Graphs showing modeled and and observed water levels ...................................................... 27

11. Graph and map showing observed and modeled shoreline linear regression rates for the period of 2005-2007.....

\section{Tables}

1. Characteristics and percent occurrence for each wave condition of the wave climatology............. 10

2. Amplitudes and phases of morphological tide constituents........................................................ 10

3. Mean values, coefficient of determination, normalized root mean squared error, mean bias, mean normalized bias, slope, and intercept of linear fit between modeled and observed stream-wise velocity components and volumetric flow rates during ebb and flood tide.

4. Coefficient of determination, mean bias, mean normalized bias, root mean squared error, and normalized RMSE statistics between observed and modeled significant wave height, peak period, average period, direction, and average direction at two nearshore wave-gage stations 20

5. Results of a sensitivity test to wind forcing....

6. Results of a classical tidal harmonic analysis of the applied water-level forcing and the observed water levels at station 8735180 .

7. Coefficient of determination, mean bias, mean normalized bias, root mean square error and normalized RMSE statistics between observed and modeled shoreline linear regression rates by island segment

\section{Appendix 1}

1.1. Model parameter and settings for the FLOW portion of the deterministic applications as set in model master definition file.

1.2. Model parameters and settings for the WAVE portion of the deterministic applications as set in model master definition wave file

1.3. Model parameter and settings for the morphology portion of each deterministic application as set in model morphology file

1.4. Model parameter and settings for the FLOW portion of the mormerge application as set in model master definition file.....

1.5. Model parameter and settings for the WAVE portion of the mormerge application as set in model master definition wave file

1.6. Model parameter and settings for the morphology portion of the mormerge application as set in model morphology file 


\section{Conversion Factors}

International System of Units to U.S. customary units

\begin{tabular}{|c|c|c|}
\hline Multiply & By & To obtain \\
\hline \multicolumn{3}{|c|}{ Length } \\
\hline centimeter $(\mathrm{cm})$ & 0.3937 & inch (in.) \\
\hline millimeter (mm) & 0.03937 & inch (in.) \\
\hline meter $(\mathrm{m})$ & 3.281 & foot $(\mathrm{ft})$ \\
\hline kilometer $(\mathrm{km})$ & 0.6214 & mile (mi) \\
\hline kilometer $(\mathrm{km})$ & 0.5400 & mile, nautical (nmi) \\
\hline meter $(\mathrm{m})$ & 1.094 & $\operatorname{yard}(\mathrm{yd})$ \\
\hline \multicolumn{3}{|c|}{ Volume } \\
\hline cubic meter $\left(\mathrm{m}^{3}\right)$ & 264.2 & gallon (gal) \\
\hline cubic meter $\left(\mathrm{m}^{3}\right)$ & 0.0002642 & million gallons (Mgal) \\
\hline cubic meter $\left(\mathrm{m}^{3}\right)$ & 35.31 & cubic foot $\left(\mathrm{ft}^{3}\right)$ \\
\hline cubic meter $\left(\mathrm{m}^{3}\right)$ & 1.308 & cubic yard $\left(\mathrm{yd}^{3}\right)$ \\
\hline cubic meter $\left(\mathrm{m}^{3}\right)$ & 0.0008107 & acre-foot (acre-ft) \\
\hline \multicolumn{3}{|c|}{ Flow rate } \\
\hline cubic meter per second $\left(\mathrm{m}^{3} / \mathrm{s}\right)$ & 70.07 & acre-foot per day (acre-ft/d) \\
\hline meter per second $(\mathrm{m} / \mathrm{s})$ & 3.281 & foot per second $(\mathrm{ft} / \mathrm{s})$ \\
\hline cubic meter per second $\left(\mathrm{m}^{3} / \mathrm{s}\right)$ & 22.83 & million gallons per day $(\mathrm{Mgal} / \mathrm{d})$ \\
\hline
\end{tabular}

\section{Datum}

Vertical coordinate information is referenced to the North American Vertical Datum of 1988 (NAVD 88).

\section{Abbreviations}

$\begin{array}{ll}\text { 1/2dt } & \text { half time-step } \\ \text { 2D } & \text { Two-dimensional } \\ \text { 3D } & \text { Three-dimensional } \\ \text { ADCP } & \text { acoustic Doppler current profiler } \\ \text { AWAC } & \text { acoustic wave and current sensor } \\ \text { Cm } & \text { centimeter } \\ \text { CONED } & \text { Coastal National Elevation Database } \\ \text { cy } & \text { cubic yard } \\ \text { D } & \text { rotation angle } \\ \text { D3D } & \text { Delft-3D } \\ \text { D } & \text { average direction } \\ \text { D } & \text { peak direction } \\ \text { deg } & \text { degree } \\ \text { dL } & \text { transect length } \\ \text { DEM } & \text { Digital elevation model } \\ \text { ECMWF } & \text { European Center for Medium-Range Weather Forecast } \\ \text { EDRC } & \text { Engineering Research and Development Center }\end{array}$




\begin{tabular}{|c|c|}
\hline EFM & Energy flux method \\
\hline ERA & ECMWF re-analysis \\
\hline GFS & Global Forecasting System \\
\hline $\mathrm{H}_{\mathrm{m}} \mathrm{O}$ & zeroth-moment wave height \\
\hline $\mathrm{H}_{\mathrm{s}}$ & significant wave height \\
\hline HYCOM & Hybrid Coordinated Ocean Model \\
\hline $\mathrm{Hz}$ & Hertz \\
\hline JONSWAP & Joint North Sea Wave Project \\
\hline lidar & Light detection and ranging \\
\hline LRR & Linear regression rate \\
\hline $\mathrm{m}$ & meter \\
\hline mdf & model master definition file \\
\hline.$m d w$ & model master definition wave file \\
\hline MHW & mean high water \\
\hline $\mathrm{mm}$ & millimeter \\
\hline mor & model morphology file \\
\hline $\mathrm{N}$ & number of observations in a record \\
\hline NAVD 88 & North American Vertical Datum of 1988 \\
\hline NDBC & National Data Buoy Center \\
\hline NGDC & National Geophysical Data Center \\
\hline NOAA & National Oceanographic and Atmospheric Administration \\
\hline Q & volumetric flow rate \\
\hline $\mathrm{R}^{2}$ & coefficient of determination \\
\hline RMSE & root mean square error \\
\hline s & second \\
\hline $\mathrm{T}_{\mathrm{a}}$ & average period \\
\hline $\mathrm{T}_{\mathrm{p}}$ & peak period \\
\hline USACE & U.S. Army Corps of Engineers \\
\hline USGS & U.S. Geological Survey \\
\hline$U$ & $x$-direction component of velocity \\
\hline V & $y$-direction component of velocity \\
\hline$U_{\text {avg }}$ & $x$-direction component of the average velocity vector \\
\hline$V_{\text {avg }}$ & $y$-direction component of the average velocity vector \\
\hline$U_{\text {stream }}$ & through-channel velocity \\
\hline$V_{\text {stream }}$ & cross-channel velocity \\
\hline Wn & weight value \\
\hline WW3 & WaveWatch III \\
\hline Z & depth \\
\hline$Z_{n}$ & bin-specific bed level data \\
\hline
\end{tabular}




\title{
Development of a Process-Based Littoral Sediment Transport Model for Dauphin Island, Alabama
}

\author{
By Robert L. Jenkins III, ${ }^{1}$ Joseph W. Long, ${ }^{2}$ P. Soupy Dalyander, ${ }^{3}$ David M. Thompson, ${ }^{4}$ and
} Rangley C. Mickey ${ }^{4}$

\begin{abstract}
Dauphin Island, Alabama, located in the Northern Gulf of Mexico just outside of Mobile Bay, is Alabama's only barrier island and provides an array of historical, natural, and economic resources. The dynamic island shoreline of Dauphin Island evolved across time scales while constantly acted upon by waves and currents during both storms and calm periods. Reductions in the vulnerability and enhancements to the resiliency of Dauphin Island - through offshore sand placement, breach closure, berm construction, and other means - have been used to protect the island and its vital resources. Planning for a resilient Dauphin Island requires predicting the long-term evolution of the barrier island system and the dominant, temporally varying processes that influence it, including littoral alongshore sediment transport under typical wave conditions, beach and dune erosion, the island overwash and breaching that occur rapidly during storm events, and the recovery of primary sand dunes through Aeolian transport over decadal time scales. Littoral sediment transport within the Dauphin Island decadal-scale framework was simulated using the Delft-3D modeling software suite. The influences of wind, waves, water levels, and sediment transport are incorporated into the model. Model skill in the prediction of waves, water levels, currents, volumetric flow rates through inlets, and shoreline position was assessed by using a set of deterministic and statistical hindcast simulations. The Delft-3D modeling application described here can be coupled with validated models of storm-response and dune recovery to predict the evolution of Dauphin Island on decadal time scales.
\end{abstract}

\section{Introduction}

Dauphin Island, Alabama, located in the northern Gulf of Mexico, just outside of Mobile Bay, is Alabama's only barrier island. The island supports sensitive populations of shorebirds, sea turtles, and other wildlife, as well as the town of Dauphin Island, which is situated on the island's east end. Historical, natural, and economic resources make this an area of importance. As a result, numerous activities have been used to enhance the resiliency of the island (for example, offshore sand placement, berm construction, and breach closure). Waves and currents during storms and calm periods shape both the natural and restored areas of the island across varied time scales. Understanding and predicting the long-term evolution of Dauphin Island and the processes that

${ }^{1}$ Cherokee Nation Technologies

${ }^{2}$ U.S. Army Corp of Engineers

${ }^{3}$ University of North Carolina at Wilmington

${ }^{4}$ U.S. Geological Survey 
shape it are vital to planning management actions that can ensure a resilient barrier island system capable of supporting its critical resources.

Various processes, across multiple temporal scales, must be considered when modeling barrier island evolution. These processes include littoral alongshore sediment transport under quiescent wave conditions that can cause the elongation, narrowing, or widening of the barrier on annual time scales; the beach and dune erosion, overwash, and breaching that occur in a matter of hours during storm events; and the recovery of primary sand dunes through aeolian transport over decadal time scales. Because these processes occur across different spatial and temporal scales and the physics associated with them vary, different modeling approaches are necessary.

As part of a larger project to develop and integrate models for each of these processes (https://coastal.er.usgs.gov/alabama-barrier-island-restoration-study/), a modeling system was developed to characterize and efficiently simulate the annual to decadal-scale littoral sediment transport and resultant morphological response along Dauphin Island, Alabama. The modeling system uses the Delft-3D (D3D) modeling software suite (Deltares, 2018a), which integrates the influences of wind, waves, water levels, and sediment transport. Skill in the model's prediction of waves, water levels, currents, volumetric flow rates associated with ebb and flood tides through inlets, and shoreline position was quantified through a set of deterministic and statistical hindcast simulations. The sensitivity of the model to wind forcing was also assessed.

The objectives of this report are to:

- Describe the modeling system methods and observations used in validation.

- Demonstrate model skill at predicting hydrodynamics, including water levels, water velocities, volumetric flow rates, and wave characteristics.

- Demonstrate model ability to predict annual to decadal morphology evolution using a statistical wave binning approach.

\section{Model Setup}

\section{Numerical Models}

\section{Hydrodynamic and Sediment Transport Model}

Delft-3D is an integrated numerical modeling system and software suite composed of modules for simulating hydromorphodynamics. D3D can be used to model a variety of phenomena including tides, wind, density- and wave-driven flows, sediment transport, and morphologic evolution in coastal and riverine environments. D3D FLOW solves either the depth averaged (twodimensional [2D] applications) or full, nonlinear, shallow-water equations (three-dimensional [3D] applications) derived from the 3D Navier-Stokes equation for incompressible free-surface flow (Lesser and others, 2004; Deltares, 2018a). Depending on the configuration, D3D can account for barotropic and baroclinic effects, turbulence, tidal forcing, space and time varying wind and bottom shear-stresses, space and time varying atmospheric pressure, and intermittent drying and flooding. When coupled with D3D WAVE, the model accounts for wave radiation stress gradients that drive nearshore circulation. By solving the spectral action density equation, D3D WAVE accounts for the propagation, shoaling, refraction, and dissipation of wind-driven surface gravity waves in coastal waters. Dissipation as a result of bottom friction, white-capping, and depth-induced breaking are 
included (Booji and others, 1999; Deltares, 2018b). When WAVE and FLOW are coupled, wavecurrent interactions, including current-induced frequency shifting, are simulated.

The sediment transport module of D3D solves the equation for suspended load transport while also accounting for sediment concentration, 3D flow velocities, eddy diffusivity, and sediment settling velocity. Breaking-wave induced shear stresses, surface mass flux, and bed shear stress under nonbreaking waves are also accounted for in both the mobilization and transport of bedload and suspended sediments. Variable and depth-dependent bed friction coefficients may be applied in the calculations. Bedload transport of noncohesive sediments accounts for bed-slope, bed composition, and the concentration of available sediment. When fluxes of sediment are allowed between bed and suspended sediment loads, the net fluxes result in bathymetric changes. This morphological updating of the bed affects flow and wave calculations at subsequent time steps. Finally, a morphological time-scale factor ("morfac") may be applied, which accelerates the rate of morphological change and compensates for the longer time scale of morphological change relative to the time scale of hydrodynamic flows. Applying a morphological time-scale factor increases the computational efficiency.

The prediction of morphology using fully deterministic simulations is not computationally feasible for time scales on the order of months to years. Instead, a schematization of wave conditions can be used to simulate coastal evolution over these temporal scales (as in Walstra and others, 2013). "Mormerge" is a specific configuration of D3D that allows a computationally efficient prediction of morphological change by simultaneously simulating the wave, flow, and sediment transport associated with multiple wave conditions. The approach periodically combines the morphological change results from each simulation to produce a cumulative morphological change that combines the effects of all wave conditions over a given period of time. Figure 1 illustrates the mormerge algorithm process. Multiple D3D model scenarios are initialized simultaneously using the same initial digital elevation model (DEM) and run in parallel. Each scenario can have unique wind, wave, and water-level forcing and a percent-occurrence, or weight, associated with how often that forcing occurs. Each scenario evolves the initial DEM at user-set intervals and the mormerge software combines the evolved topography and bathymetry from each scenario using a weighted average, where the weight of each scenario is equal to a percent occurrence of that wave condition. The resulting weighted-average bathymetry is applied to all scenarios for the next time interval. The set of unique forcing scenarios simulate again, using an identical bathymetry, and evolve independently until the next merging interval. The product of mormerge is a change in morphology that accounts for the effects of all the individual scenarios, and therefore the effects of the full range of regional wave conditions (Deltares, 2018a).

\section{Model Setup and Coupling}

A coupled D3D FLOW-WAVE depth-averaged 2D application was developed for the Dauphin Island barrier island system and the adjacent coastal region. The study area encompasses the entirety of Mobile Bay to the north, parts of Gulf Shores, Ala., to the east, the coastal shelf region to approximately the 30 meter $(\mathrm{m})$ depth contour to the south, and the eastern end of Petit Bois Island, Miss., to the west (fig. 2). This extent was chosen to include Dauphin Island, all the inlets that immediately surround it, and elements of the offshore coastal bathymetry that affect wave propagation to the nearshore. The extent was also chosen to maximize numerical stability, minimize artificial boundary effects near Dauphin Island, and allow for computational efficiency. 
The modeling system uses three computational grids. The WAVE module uses two grids to simulate wave propagation and eventual dissipation near the island. The first grid is a coarsely resolved curvilinear grid consisting of 245 (alongshore) x 449 (cross-shore) grid points that covers the extent of the study area and serves as the outer wave domain. The outer coarse wave grid has a variable alongshore resolution ranging from $250 \mathrm{~m}$ to $325 \mathrm{~m}$ and a variable cross-shore resolution ranging from $15 \mathrm{~m}$ closer to the island and Mobile Bay Inlet to 300-m grid spacing offshore. The inner fine wave grid is nested within the outer grid and designed to resolve the surf zone along Dauphin Island to capture the depth-induced wave breaking that drives alongshore currents and sediment transport in the nearshore.

The fine wave grid consists of 1,367 (alongshore) x 458 (cross-shore) grid points with variable cross-shore resolution ranging from an approximate 5-m grid spacing close to the island to over 250-m to the south and north. The alongshore resolution of the fine wave grid ranges from a 40-m grid spacing along the island and across the span of the Petit Bois and Mobile Bay inlets to a 100-m grid spacing at points east of Mobile Bay. The fine wave grid is limited longitudinally so that the east and west lateral boundaries extend from Fort Morgan Peninsula in Alabama and the eastern tip of Petit Bois Island, respectively. The latitudinal limits of the fine wave grid extend from the nearshore of Dauphin Island to north of Little Dauphin Island, excluding much of Mobile Bay (fig. 2).

The FLOW module uses a single curvilinear grid that consists of 1,368 (alongshore) $\mathrm{x}$ 657 (cross-shore) grid points with variable alongshore and cross-shore resolution that covers the extent of the study area. Consistent with the fine wave grid, cross-shore resolution of the flow grid ranges from a less than 5-m grid spacing close to the island to an over 300-m grid spacing in the northernmost reaches of Mobile Bay. The alongshore resolution of the flow grid ranges from a 40-m grid spacing along the island and across the span of Petit Bois and Mobile Bay inlets to a 100-m grid spacing east of Mobile Bay. Coefficients of bottom friction are spatially varied throughout the domain and are depth dependent, as described in Passeri and others (2018b). Model parameter settings for sediments were based on the observation of Ellis and others (2017).

The FLOW and WAVE modules are coupled in a two-way configuration in which timedependent bathymetry, water velocities, water levels, and winds are passed from FLOW to WAVE and radiation stress gradients created by wave breaking are passed back from WAVE to FLOW. For a complete list of model inputs and parameters, see appendix 1. 


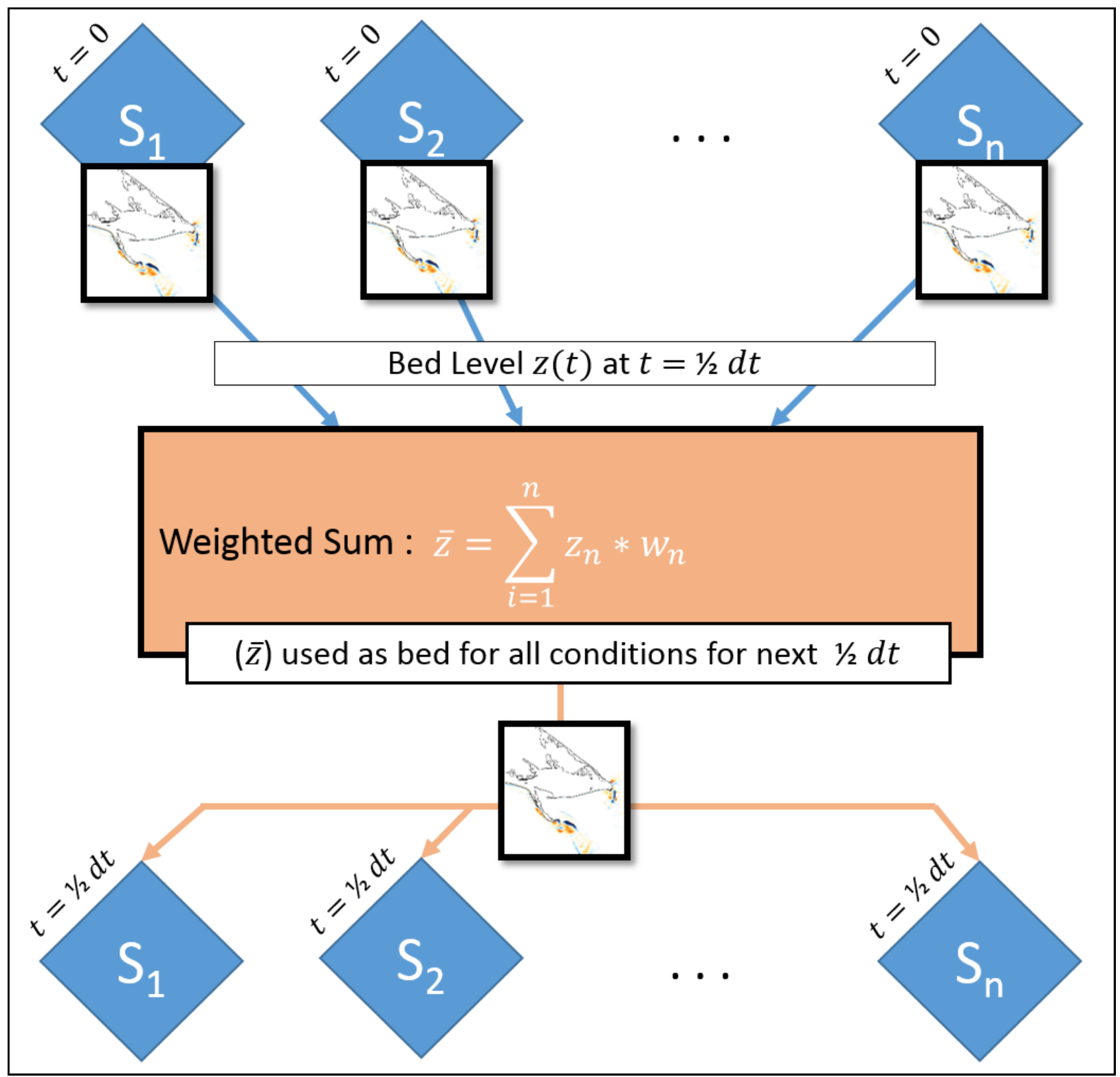

Figure 1. Flow chart in which $\mathrm{S}_{1}, \mathrm{~S}_{2}, \ldots \mathrm{S}_{n}$ (with inset thumbnail maps of the study area) represent hydrodynamic forcing conditions at various simulation timesteps $(\mathrm{t})$. Each scenario is a variation on the same simulation and has an associated weight value $\left(w_{n}\right)$ based on the percent occurrence in the historical record. Each scenario must have the same initial bathymetry $(z)$ and morphological parameterization but may have varying boundary conditions, wind, and wave forcing. All scenarios initialize and run simultaneously and exchange bed level data $\left(z_{n}\right)$ at each half time-step $(1 / 2 d t)$. A weighted sum of all bed levels $(\bar{z})$ is calculated, and that weighted sum is distributed to each scenario and used as the bed level for the next half time-step. This process is repeated throughout the mormerge simulation such that the final result is a bed level that represents the cumulative effect of all the scenarios. 


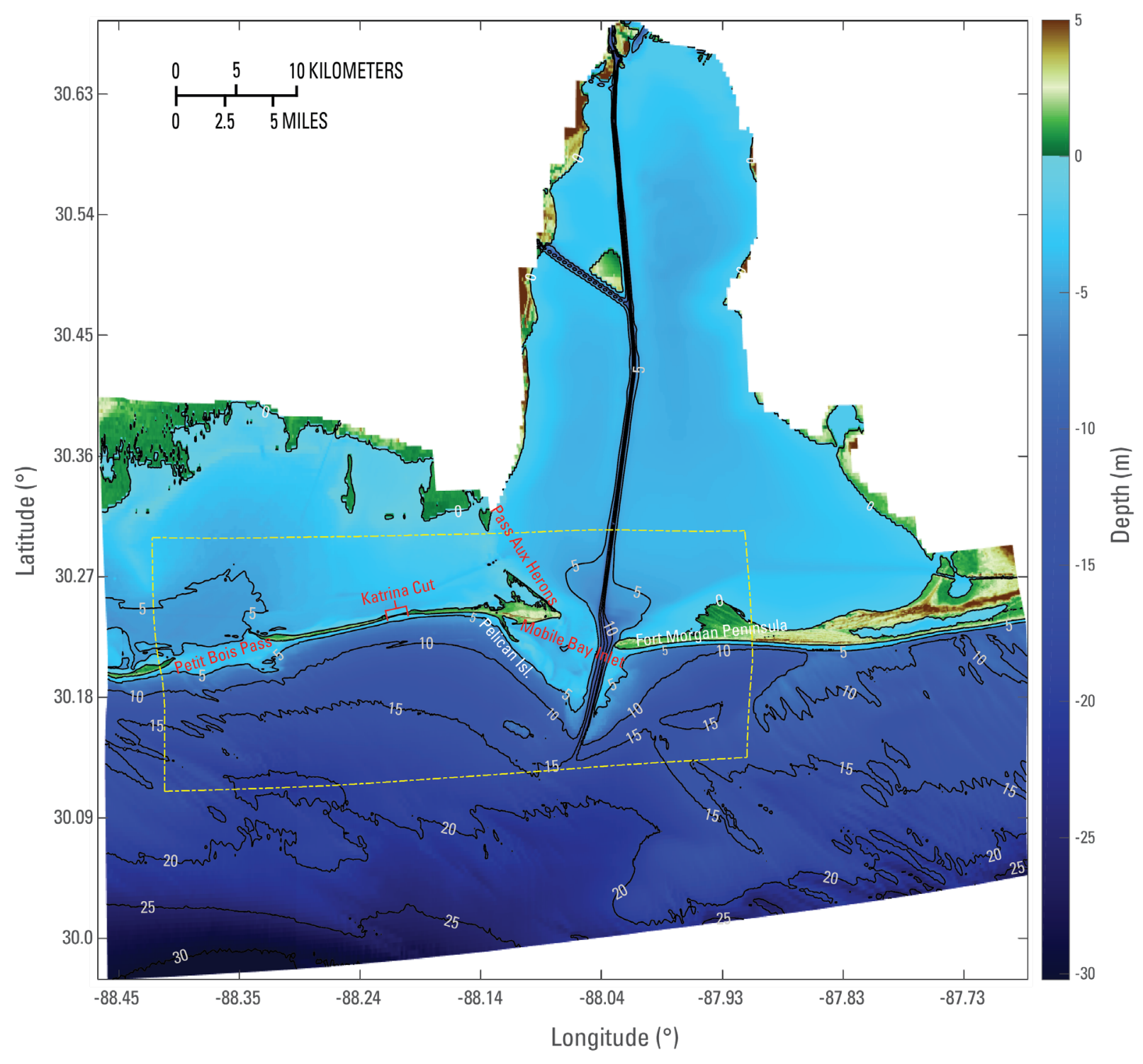

Figure 2. Map showing the study area and digital elevation model (DEM) for this report. Depth contours indicate 0-, 5-, 10-, 15-, 20-, 25-, and 30-meter (m) isobaths (black lines). The domain pictured shows the full extent of the flow grid and coarse wave grid. The extent of the fine wave grid is shown with a yellow dash-dotted line.

\section{Topobathymetric Data and Digital Elevation Models}

Two DEMs were developed for the deterministic and climatological applications, and both used available light detection and ranging (lidar) data to characterize the initial shape of the subaerial island and the respective shoreline position at the start of each run. The first DEM corresponded to Dauphin Island in 2015 and the second to Dauphin Island after Hurricane Katrina in late 2005. Each DEM shared Coastal National Elevation Data (CONED) (Danielson and others, 2013) and National Geophysical Data Center (NGDC) topographic and bathymetric data, which supplied elevation information for broad swaths of the study area, including the upper bay, 
offshore, Petit Bois, and Gulf Shores areas not covered by lidar data during the time periods of interest (National Oceanic and Atmospheric Administration, 2009). Portions of the 2015 DEM, including the island shoreline position and topography, were also updated with bathymetry data from a 2015 survey that covered only the nearshore regions immediately surrounding Dauphin Island (Flocks and others, 2015; Dewitt and others, 2017).

For the 2005 post-Katrina DEM, the island shoreline position and topography were provided by USGS lidar survey data (Kranenburg and others 2016; Thompson and others, 2017) collected immediately after Hurricane Katrina, dated 2005/09/04. The updated bathymetric coverage of Mobile Bay was provided by the U.S. Army Corps of Engineers (USACE) Mobile District and incorporated into the 2015 DEM, as outlined by Passeri and others (2018a). For the 2005 post-Katrina DEM, no updated bathymetric data were available for the nearshore region. In this case, the nearshore bathymetry was taken as the final bottom depth from an independently validated simulation of Dauphin Island using an XBeach (Roelvink and others, 2009) simulation of Hurricanes Ivan and Katrina (Passeri and others, 2018b) to characterize the movement of sand that occurred from the island to the nearshore and estuarine areas during Hurricane Katrina.

\section{Deterministic Application}

A deterministic application of the model was used to compare model outputs to in situ observations of waves and currents. Deterministic applications of the model to the Dauphin Island region were forced with time-dependent waves, wind, and water levels derived from largerscale models. The model was applied during time periods when nearshore observations of waves, water levels, and currents were available for model validation, from 2015/08/27-2015/08/29 and 2015/12/09-2015/12/11 for ADCP observations, and 2015/06/19-2015/11/20 for wave observations. Observation locations are shown in figure 3. Waves were forced at the offshore boundary with JONSWAP (Joint North Sea Wave Project) spectra (Hasselmann and others, 1973) created using a 3-hourly output from the National Oceanic and Atmospheric Administration (NOAA) operational WaveWatch III (WW3) (Tolman, 1989) model, which included significant wave height $\left(H_{s}\right)$, peak period $\left(T_{p}\right)$, and peak direction $\left(D_{p}\right)$. Using these large-scale wave predictions rather than spatially discrete wave-buoy observations allows for alongshore non-uniformity in wave conditions at the offshore boundary. Long and others (2014) showed that WW3 modeled wave information compared well with observed waves at the National Data Buoy Center (NDBC) buoy offshore of Orange Beach, Alabama.

Along both lateral boundaries, D3D WAVE was used to compute the cross-shore variation of the incident spectra by performing standalone wave simulations over straight and parallel contours that mimic the cross-shore bathymetry at the individual boundaries. Wind forcing was applied to both the FLOW and WAVE modules at 3-hour intervals using WaveWatchIII associated Global Forecast System (GFS) 10-meter wind speed and directions (Tolman, 1989). This wind forcing was chosen over locally observed wind speeds at the NDBC offshore buoy because it provides spatially varying wind characteristics over the entire domain and is the same source of wind values used to generate the WW3 wave inputs. Water levels, including tides, were derived from HYCOM and applied at the southern offshore open boundary at hourly intervals (Bleck, 2002). An initial analysis found a 21-centimeter (cm) offset between HYCOM water levels and observed water levels at NOAA Dauphin Island tide gage 8735180 (fig. 4) (National Oceanic and Atmospheric Administration, 2017). A 21-cm offset was therefore added to the HYCOM water levels before they were applied to the model. Water levels were only applied to the southern open 
boundary to avoid numerical instabilities caused by fixing water levels too close to shore along the eastern and western open boundaries. The deterministic simulations were initialized at rest and allowed to spin-up for a period of 6 hours prior to the beginning of observations.

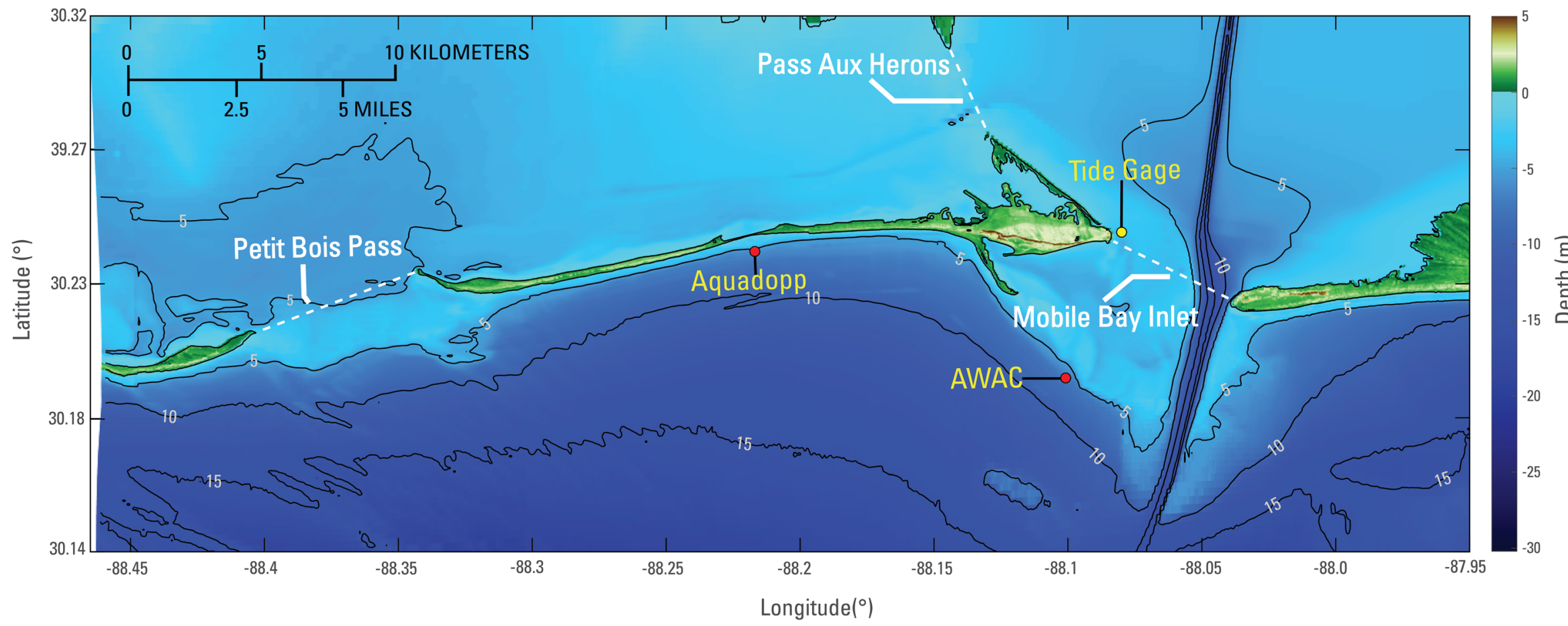

Figure 3. Colored map of the digital elevation model (DEM) for this model showing observation locations within the study area. Depth contours indicate 5-, 10-, 15-meter (m) isobaths (black lines). Acoustic Doppler current profile (ADCP) transect observations locations in Mobile Bay Inlet, Pass Aux Herons, and Petit Bois Pass are shown with white dotted lines. Deployed wave-gage locations offshore of Katrina Cut and on the ebb tidal shoal are shown with red circles. National Oceanic and Atmospheric Administration (NOAA) tide gage location at Dauphin Island (station 8735180) is shown with a yellow circle. 

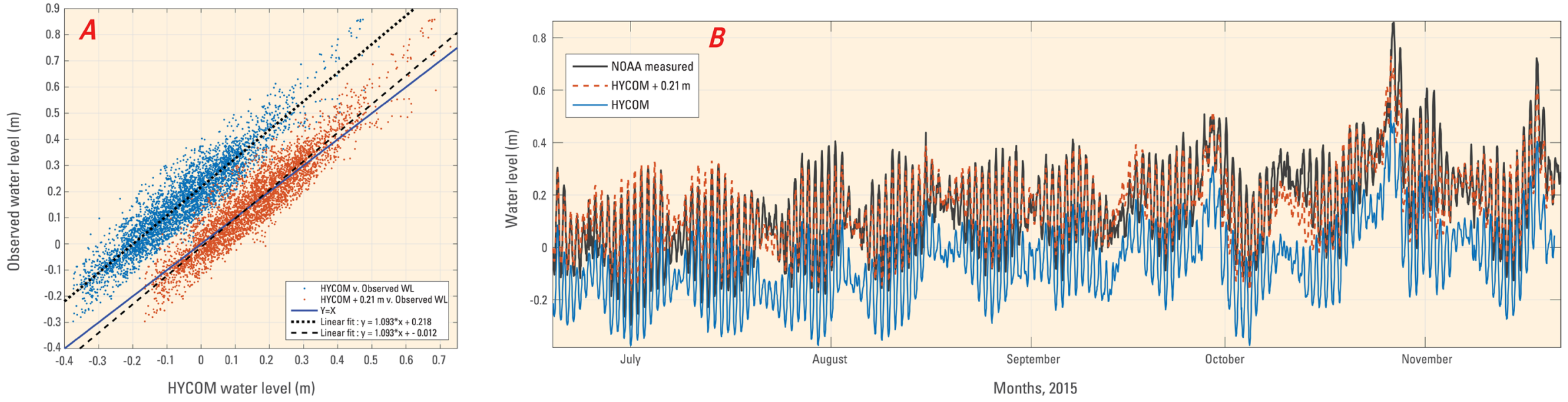

Figure 4. Graphs showing water-level observations and Hybrid Coordinated Ocean Model (HYCOM) data at Dauphin Island, Alabama for a 6-month period. (A) Scatter plot of HYCOM water levels versus observed water levels at Dauphin Island tide gage (blue dots) and scatter plot of HYCOM water levels plus 21 centimeters (cm) versus observed water levels at Dauphin Island tide gage (orange dots). Line of $y=x$ is shown in blue. The line of best fit is shown for each scatter with black dotted and dashed lines, respectively. The equation of fit for each scatter plot is also shown. (B) 6-month time series of water-level observations and HYCOM model data at Dauphin Island. Tide gage illustrates offset between unmodified HYCOM water levels. NOAA measured water levels at Dauphin Island tide gage (8735180) are shown with a black line. Unmodified HYCOM water levels are shown by a blue line. A time series of HYCOM water levels plus $21 \mathrm{~cm}$ is shown is orange. NOAA, National Oceanic and Atmospheric Administration.

\section{Climatological Application}

For the application of mormerge at Dauphin Island, regional wave conditions were derived from the European Centre for MediumRange Weather Forecast (ECMWF) Reanalysis (ERA)-Interim model (Dee and others 2011) and adjusted by a correction factor attained through comparison to wave height data from NDBC buoy 42040 (National Data Buoy Center, 2017a; Passeri and others, 2018a). This time series provided the longest record of wave data (1979-present) relative to the shorter WW3 (2005-present) or observational NDBC (1983-1984 and 2009-present) records. $H_{s}, T$, and $D_{p}$, at a model grid point located offshore of Dauphin Island (lat $30.000^{\circ} \mathrm{N}$, long $-88.125^{\circ} \mathrm{W}$ ) were used to define the regional wave conditions. Time periods with waves not directed toward shore between $110^{\circ}$ and $250^{\circ}$ (nautical convention) were excluded, given that they would not propagate into the model domain and drive longshore transport. Time periods containing tropical events were also excluded from the wave binning, as this D3D model only simulates decadal-scale littoral transport for quiescent periods.

The binning of the wave conditions was defined such that all bins contained equal amounts of wave-energy flux following the energy flux method (EFM) of Benedet and others (2016). The wave conditions were divided into nine wave bins delimited by three directions and three heights. Nine scenarios were developed using the binned information. The wave period $\left(T_{a}\right)$ of each scenario is the mean period of all waves within each bin, wave direction $\left(D_{a}\right)$ is the mean direction of the wave conditions in each bin, and wave height $\left(H_{s}\right)$, assuming linear 
wave theory, is calculated from the mean wave-energy flux of all wave conditions in each bin. The percent occurrence is calculated as the number of ERA wave data points contained in a bin divided by the total number of ERA wave data points in the record. $H_{s}, T_{a}, D_{a}$, and the percent occurrence of each of the nine scenarios are given in table 1 . Nine wave scenarios were used for computational efficiency while also exceeding the noted lower limitation of the six wave scenarios outlined by Benedet and others (2016). Along both lateral boundaries, D3D WAVE was used to compute the cross-shore variation of the incident spectra for each scenario by performing standalone wave simulations over straight and parallel contours that mimic the cross-shore bathymetry at the individual boundaries, similar to the deterministic application.

Water-level forcing is applied to the model at the southern open boundary as a morphological tide derived using the method outlined by Lesser (2009). This method uses observed amplitudes and phases obtained at the Dauphin Island NOAA tide gage (8735180) to generate constituent amplitudes and phases representative of the observed water-level conditions without being date-range specific. The tide constituents were applied to each of the mormerge scenarios with a consistent and progressive phase shift that was added to improve model stability. Constituent amplitudes and phases of the derived morphological tide are given in table 2. Neumann boundary conditions are applied to the east and west lateral boundaries. The mormerge application is initialized at rest, and a morphological start time of 6 hours is applied. This allows time for the mean alongshore total transport to spin-up to a quasi-steady state before the morphology is allowed to evolve. A morfac of 365 is used in all cases, such that 1 day in the model simulation represents 365 days of morphologic evolution. Local wind forcing is not included in the mormerge application given that the predominant driver of waves seaward of Dauphin Island is expected to be generated outside of the model domain; resultant wave-driven currents, along with tides, are expected to be the dominant driver of nearshore circulation on the Gulf-side of the island. Overall model sensitivity to wind forcing, in terms of reproducing waves, was assessed. Results of this sensitivity study are presented in the Results section of the report.

Table 1. Characteristics and percent occurrence for each wave condition of the wave climatology. [m, meters; \% percent; s, seconds]

\begin{tabular}{llccc}
\hline Condition name & $\mathbf{H}_{\mathbf{s}}(\mathbf{m})$ & $\mathbf{T}_{\mathbf{a}}(\mathbf{s})$ & $\mathbf{D}_{\mathbf{a}}$ (degrees) & Occurrence $(\%)$ \\
\hline Bin 1 & 0.5275 & 6.2007 & 129.4898 & 26.054 \\
Bin 2 & 0.57721 & 6.3974 & 154.7268 & 24.523 \\
Bin 3 & 0.57327 & 5.7028 & 200.7705 & 28.165 \\
Bin 4 & 1.1401 & 7.1784 & 128.7983 & 5.684 \\
Bin 5 & 1.1299 & 7.4228 & 155.1817 & 5.5534 \\
Bin 6 & 1.1841 & 7.0636 & 197.2398 & 5.3663 \\
Bin 7 & 2.1797 & 8.4778 & 127.9215 & 1.3379 \\
Bin 8 & 1.9525 & 8.4175 & 155.7543 & 1.7199 \\
Bin 9 & 2.0213 & 8.3957 & 199.2142 & 1.5971 \\
\hline
\end{tabular}

Table 2. Amplitudes and phases of morphological tide constituents. [deg, degrees; Hz, hertz; m, meters]

\begin{tabular}{lcr}
\hline \multicolumn{1}{c}{ Measured element } & $\mathbf{1 5 ~ H z}$ & $\mathbf{3 0 ~ H z}$ \\
\hline Amplitude (m) & 0.19727139 & 0.0015 \\
Phase (deg) & 321.194 & 310.5783 \\
\hline
\end{tabular}




\section{Observations}

Output from the deterministic model was compared with observations of waves, water levels, and tidal currents to assess the skill of the hydromorphological modeling system for Mobile Bay and Dauphin Island, Alabama. Due to limited direct observations of sediment transport and morphology change in the nearshore, observations of shoreline positions and shoreline linear regression rates were used as a proxy for littoral sediment transport to compare to the model.

\section{Hydrodynamic Data}

As part of the Alabama Barrier Island Restoration Study, two ship-board acousticDoppler current profile (ADCP) surveys were carried out during spring tide conditions by the USACE Engineering Research and Development Center (ERDC), Field Data Collection Branch. At the time of publication, data are not publicly available from USACE. Each ADCP survey traversed the three major inlets surrounding Dauphin Island: Mobile Pass, Pass Aux Herons, and Petit Bois Pass (fig. 3). Data were captured along transects at an approximate 3.5-m horizontal resolution. Each survey captured approximately half of a tidal cycle (approximately 12 hours). The first survey, which collected data during the period of 2015/08/27, 12:01:00 through 2015/08/28, 00:35:00, captured primarily ebb tide conditions. The second survey, which collected data during the period of 2015/12/09, 13:02:00 through 2015/12/09, 23:59:00, primarily captured the characteristics of a flood tide. However, the first survey also captured several passes during flood and slack tide conditions, while the second survey captured passes during slack tide conditions. Data were collected at a frequency of $0.4 \mathrm{Hertz}(\mathrm{Hz})$.

The ADCP captured horizontal position, water depth, and horizontal and vertical components of flow velocities from which stream-wise velocity components and volumetric flow rates were derived. Stream-wise velocity components were calculated from water velocities by first finding the average velocity vector, defined by the average velocity component vectors, $u_{\text {avg }}$ and $v_{\text {avg }}$ in the original coordinate system. The rotation angle (equation 1) from the original coordinate system to the stream-wise coordinate system in degrees $(D)$, is defined as:

$$
D=\tan ^{-1}\left(\frac{v_{\text {avg }}}{u_{\text {avg }}}\right) * \frac{180}{\pi}
$$

So that the stream-wise velocity components can be calculated as:

$$
\begin{gathered}
u_{\text {stream }}=u \cos \left(D \frac{180}{\pi}\right)+v \sin \left(D \frac{180}{\pi}\right) \\
v_{\text {stream }}=-u \sin \left(D \frac{180}{\pi}\right)+v \cos \left(D \frac{180}{\pi}\right)
\end{gathered}
$$

where
$D$
the rotation angle from the original coordinate system to the stream-wise coor- dinate system in degrees; the y-direction component of the average velocity vector; the $\mathrm{x}$-direction component of the average velocity vector; the through-channel velocity, regardless of the geographic orientation of the inlet channel to the original coordinate system; 
$v_{\text {stream }} \quad$ the cross-channel velocity, regardless of the geographic orientation of the inlet channel to the original coordinate system;

$u \quad$ the $\mathrm{x}$-direction component of velocity; and

$v \quad$ the $\mathrm{y}$-direction component of velocity.

Volumetric flow rate (equation 4), or flux, through each transect through time was calculated using the stream-wise $u$ velocity, as

$$
Q=d L * \sum u_{\text {stream }} * Z
$$

where
$Q \quad$ the volumetric flow rate;
$d L \quad$ the length of each transect; and
$z \quad$ the depth.

Two directional wave gage and current profilers were also deployed in the nearshore areas of Dauphin Island by the USACE. A Nortek acoustic wave and current (AWAC) sensor was deployed near Pelican Island in the area of the Mobile Pass ebb tidal shoal at lat $30.242248^{\circ}$ N., long $88.2125^{\circ} \mathrm{W}$ (fig. 3). The sensor sampled pressure and velocity at a rate of $2 \mathrm{~Hz}$ and returned frequency-direction wave spectra, hourly bulk-wave statistics, pressure, and water velocities at 5-minute intervals for the period of 2015/08/31-2015/11/20. A bottom-mounted Nortek Aquadopp wave sensor was deployed in the surf zone near Katrina Cut at lat $30.200543^{\circ}$ N., long $88.0927778^{\circ} \mathrm{W}$. The sensor sampled pressure and velocity at a rate of $2 \mathrm{~Hz}$ and returned frequency-directional wave spectra, hourly wave statistics, pressure, and water velocities at 5-minute intervals for the period of 2015/06/20-2015/08/23. At the time of publication, data are not publicly available from the USACE. Hourly historical wave data were also downloaded from the NDBC at station 42012 near Orange Beach, Ala. (National Data Buoy Center, 2017b), for time periods overlapping both the AWAC and Aquadopp observation periods to evaluate the accuracy of wave inputs derived from WW3.

Water-level data were downloaded from the NOAA Dauphin Island tide gage 8735180 (National Oceanic and Atmospheric Administration, 2017) for periods that coincided with the other hydrodynamic observation periods. Measured and predicted tides at 6-minute intervals were obtained from the Dauphin Island tide gage for the periods of 2015/08/27 through 2015/08/28, and 2015/12/09 through 2015/12/09. Measured and predicted tides of 6 minutes were also collected for the periods of 2015/08/31-2015/11/20 and 2015/06/20-2015/08/23.

\section{Shoreline Change Data}

Repeat observations of bathymetric change surrounding Dauphin Island were not available for validating the littoral sediment transport model. As a proxy, the model skill in capturing patterns of convergent and divergent alongshore sediment transport was determined using historical shoreline positions and shoreline change rates. Dauphin Island shorelines, defined as the mean high water (MHW) line (24 cm, NAVD 88) and historical rates of shoreline change were derived from historical lidar data from thirteen airborne lidar surveys that took place between 1998 and 2014 (Henderson and others, 2017). 


\section{Results}

\section{Comparison to Observations-Deterministic Simulations}

\section{Acoustic-Doppler Current Profile Comparison}

A deterministic application of the model for each of the ADCP observation periods was developed to simulate flow and wave conditions through each of the adjacent inlets. The model setup for each simulation used the 2015 DEM as the initial topobathymetric input. Each of the two simulation periods was forced with a wind, wave, and water-level time series for each representative time period: the first observation and simulation period extends from 2015/08/27 through 2015/08/29 and the second period extends form 2015/12/09 through 2015/12/11. Each simulation was set to begin at least 12 hours prior to the beginning of the observation record to allow for the spin-up of water levels and velocities in the model. Sediment transport was computed, but the morphology remained constant throughout each simulation.

From both simulation periods, modeled water velocities were interpolated from the model grid onto the observation transects in each of the inlets. Modeled and observed water velocities were then rotated to the stream-wise convention to attain through-channel velocity $\left(u_{\text {stream }}\right)$ and cross-channel velocity $\left(v_{\text {stream }}\right)$ components. Observed and modeled through-channel $u$ velocities were used to calculate observed and modeled volumetric flow rate $(Q)$ through each observation transect, as described above. Additionally, the $u_{\text {stream }}, v_{\text {stream }}$, and $Q$ of both surveys were parsed and collated so that a dataset for the ebb and flood phases of the tide cycle could be assessed separately. The $Q$ value was used to characterize survey passes as either ebb, flood, or slack tide; survey passes at slack tide were defined as having $Q$ near zero, or roughly 1 order of magnitude smaller than the mean value, while ebb and flood tide were determined by flow direction (into or out of the channel). For both the ebb and flood phases, at each observation transect, linear fits between modeled and observed values were calculated for the following variables: $u_{\text {stream }}, v_{\text {stream }}$, and $Q$. In table 3 , the coefficient of determination $\left(\mathrm{R}^{2}\right)$, normalized RMSE, mean bias, mean normalized bias, slope, and intercept values associated with each linear fit are presented.

Figure $5 \mathrm{~A}$ illustrates the $u_{\text {stream }}$ analysis in Mobile Bay Inlet for both tide phases. A scatter plot of modeled versus observed $u_{\text {stream }}$ for the ebb tide (blue dots) is given along with the line of best fit (solid black line) and shows a strong agreement between the model output and observations, with an $\mathrm{R}^{2}$ value of 0.84 . A comparison of the modeled and observed $u_{\text {stream }}$ for the second observation period (yellow dots) is also given along with the line of best fit (dashed black line). There is more scatter over the flood period than for the ebb period, which is reflected in a lower $\mathrm{R}^{2}$ value of 0.53 . Overall, figure $5 \mathrm{~A}$ demonstrates that the model reasonably predicts $u_{\text {stream }}$ in Mobile Bay Inlet during the ebb portion of the tidal cycle and is relatively less skilled in predicting $u_{\text {stream }}$ in Mobile Bay Inlet during the flood tide. However, the modeled and observed $u_{\text {stream }}$ were of a similar magnitude. The mean bias between the observed and through-channel ebbflow velocities has a magnitude of -0.19 meters per second $(\mathrm{m} / \mathrm{s})$ and a mean normalized bias of -35.1 percent, which suggests underprediction of through-channel velocities. Similarly, for the flood tide, observed and modeled $u_{\text {stream }}$ are of a similar magnitude, as shown by the mean bias of $-0.03 \mathrm{~m} / \mathrm{s}$, while the mean normalized bias is -8.14 percent.

Figure $5 B$ shows the same analysis applied to the smaller magnitude $v_{\text {stream }}$ in Mobile Bay Inlet for both ADCP observation periods. A scatter plot of modeled versus observed $v_{\text {stream }}$ for 
the first observation period (blue dots) is shown along with the line of best fit (solid black line), and it shows agreement between the model output and observations, with an $\mathrm{R}^{2}$ value of 0.62 . A comparison of the modeled and observed $v_{\text {stream }}$ for the second observation period (yellow dots) is shown along with the line of best fit (dashed black line). The associated $\mathrm{R}^{2}$ value of this linear fit is 0.45 . In both the ebb and flood tide, the mean bias statistics for $v_{\text {stream }}$ show that the magnitudes of observed and modeled velocities are similar, with near-zero mean biases. Mean normalized bias statistics for ebb and flood tide periods are 40.6 percent and -73.0 percent, respectively. As was the case for the $u_{\text {stream }}$ in Mobile Bay Inlet, these comparisons show that the model reasonably predicts $v_{\text {stream }}$ in Mobile Bay Inlet during the ebb portion of the tidal cycle and is relatively less skilled in predicting $v_{\text {stream }}$ in Mobile Bay Inlet during the flood tide.

A comparison of the model output and the observed values (table 3) highlights several aspects of model skill. First, the model skill is best in Mobile Bay Inlet for each variable examined $\left(u_{\text {stream }}, v_{\text {stream }}\right.$, and $\left.Q\right)$ compared with other inlets for both the ebb and flood phases; the model skill is similar overall in Pass Aux Herons and in Petit Bois Inlet for each variable. Second, model skill is generally higher for the dominant $u_{\text {stream }}$ than for the smaller magnitude $v_{\text {stream }}$, which is the case except in Pass Aux Herons during the ebb tide, where the $\mathrm{R}^{2}$ of $u_{\text {stream }}$ and $v_{\text {stream }}$ are comparable, and in Petit Bois Inlet during the flood tide period, where the skill is higher for the $v$ component. Third, the model shows skill in reproducing $Q$ for the ebb-tide phase everywhere, with $\mathrm{R}^{2}$ values comparable to, or exceeding, those associated with the $u$-velocity component. The ability to accurately reproduce a volumetric flow rate suggests that the bathymetry used in the model may not properly capture the depth variations across the inlets at the time the observations were collected (fig. 6), which would negatively impact the velocity predictions.

The lower model skill in Pass Aux Herons than in Mobile Bay Inlet is, in part, attributed to lower grid resolution across the Pass Aux Herons inlet, where grid resolution becomes coarser north of the island. The lower model skill in Petit Bois Inlet is attributed to an inaccurate initial bathymetry, as there was no up-to-date bathymetric data for this inlet. Figures $6 C$ and $6 F$ show a significant and consistent discrepancy of at least 1 meter between the depth on the observation transect and the initial model depth interpolated onto the observation transect. The lower model skill in producing $v_{\text {stream }}$ velocities may result from smaller magnitudes when compared with $u_{\text {stream }}$ velocities. Small deviations in modeled water-level velocities may have led to lower model skill due to the small magnitude of the overall flow. Each of these factors is likely to contribute to model error in reproducing $Q$.

Overall, the comparison to ADCP observations for each of these periods shows that the model is skilled at reproducing water velocities and volumetric flow rates in the most significant of the three inlets, Mobile Bay inlet, which has the highest through-channel velocities. Model skill is also greatest during the dominant ebb tide. The lower skill in Petit Bois Inlet can, in part, be attributed to an inaccurate initial bathymetry. The lower overall skill of the cross-channel components is accounted for by smaller overall magnitude velocities, which are more sensitive to model variability. 
where

The bias statistic presented throughout this report is calculated as

$$
\text { Bias }=\frac{1}{N} \sum_{1}^{N} \text { Modeled }- \text { observed }
$$

$$
\begin{aligned}
N & \text { the number of observations in a record; } \\
\text { Modeled } & \text { any modeled quantity; and } \\
\text { Observed } & \text { any observed quantity. }
\end{aligned}
$$

Additionally, the mean normalized bias discussed throughout this report is calculated generally as:

$$
\text { Mean Normalized Bias }=\left(\frac{1}{N} \sum_{1}^{N} \frac{\text { Modeled }}{\text { Observed }}-1\right) * 100
$$

Table 3. Mean values, coefficient of determination $\left(\mathrm{R}^{2}\right)$, normalized root mean squared error (NRMSE), mean bias, mean normalized bias (NBIAS), slope, and intercept of linear fit between modeled and ob-

\begin{tabular}{|c|c|c|c|}
\hline Flow type & Mobile Bay Inlet & Pass Aux Herons & Petit Bois Inlet \\
\hline \multicolumn{4}{|c|}{ Mean observed value } \\
\hline$u,_{e b b}(\mathrm{~m} / \mathrm{s})$ & 0.58 & 0.41 & 0.28 \\
\hline$v,_{e b b}(\mathrm{~m} / \mathrm{s})$ & $3.13 \mathrm{e}-15$ & $9.31 \mathrm{e}-17$ & $-6.90 e-15$ \\
\hline$Q,_{e b b}\left(\mathrm{~m}^{3} / \mathrm{s}\right)$ & $1.30 \mathrm{e}+07$ & $1.3998 \mathrm{e}+06$ & $9.7578 \mathrm{e}+06$ \\
\hline$u,,_{\text {flood }}(\mathrm{m} / \mathrm{s})$ & 0.32 & 0.31 & 0.24 \\
\hline$v,{ }_{\text {flood }}(\mathrm{m} / \mathrm{s})$ & $5.24 \mathrm{e}-15$ & $-7.84 \mathrm{e}-15$ & $1.68 \mathrm{e}-15$ \\
\hline$Q,{ }_{\text {flood }}\left(\mathrm{m}^{3} / \mathrm{s}\right)$ & $9.82 \mathrm{e}+06$ & $1.51 \mathrm{e}+06$ & $9.44 \mathrm{e}+06$ \\
\hline \multicolumn{4}{|c|}{$R^{2}$} \\
\hline$u,_{e b b}(\mathrm{~m} / \mathrm{s})$ & 0.84 & 0.25 & 0.45 \\
\hline$v,_{e b b}(\mathrm{~m} / \mathrm{s})$ & 0.62 & 0.36 & 0.28 \\
\hline$Q,_{e b b}\left(\mathrm{~m}^{3} / \mathrm{s}\right)$ & 0.96 & 0.57 & 0.50 \\
\hline$u,_{\text {flood }}(\mathrm{m} / \mathrm{s})$ & 0.53 & 0.16 & 0.002 \\
\hline$v,{ }_{\text {flood }}(\mathrm{m} / \mathrm{s})$ & 0.45 & 0.07 & 0.46 \\
\hline$Q,_{\text {flood }}\left(\mathrm{m}^{3} / \mathrm{s}\right)$ & 0.44 & 0.08 & 0.02 \\
\hline \multicolumn{4}{|c|}{ Normalized RMSE } \\
\hline$u,_{e b b}(\mathrm{~m} / \mathrm{s})$ & 0.08 & 0.10 & 0.13 \\
\hline$v,_{e b b}(\mathrm{~m} / \mathrm{s})$ & 0.07 & 0.16 & 0.09 \\
\hline$Q,_{e b b}\left(\mathrm{~m}^{3} / \mathrm{s}\right)$ & 0.09 & 0.25 & 0.29 \\
\hline$u,{ }_{\text {flood }}(\mathrm{m} / \mathrm{s})$ & 0.10 & 0.14 & 0.14 \\
\hline$v,{ }_{\text {flood }}(\mathrm{m} / \mathrm{s})$ & 0.09 & 0.13 & 0.05 \\
\hline$Q,{ }_{\text {flood }}\left(\mathrm{m}^{3} / \mathrm{s}\right)$ & 0.24 & 0.28 & 0.39 \\
\hline
\end{tabular}
served stream-wise velocity components (X-direction component of velocity $[u]$ and $y$-direction component of velocity $[v]$ ) and volumetric flow rates $(Q)$ during ebb and flood tide. NRMSE is normalized by the range of the data.

[ $\mathrm{m}^{3} / \mathrm{s}$, cubic meters per second; $\mathrm{m} / \mathrm{s}$, meters per second; \%, percent] 
Table 3. Mean values, coefficient of determination $\left(R^{2}\right)$, normalized root mean squared error (NRMSE), mean bias, mean normalized bias (NBIAS), slope, and intercept of linear fit between modeled and observed stream-wise velocity components ( $\mathrm{X}$-direction component of velocity $[u]$ and $\mathrm{y}$-direction component of velocity [v]) and volumetric flow rates $(Q)$ during $e b b$ and flood tide. NRMSE is normalized by the range of the data.-Continued

[ $\mathrm{m}^{3} / \mathrm{s}$, cubic meters per second; $\mathrm{m} / \mathrm{s}$, meters per second; \%, percent]

\begin{tabular}{|c|c|c|c|}
\hline Flow type & Mobile Bay Inlet & Pass Aux Herons & Petit Bois Inlet \\
\hline \multicolumn{4}{|c|}{ Mean bias } \\
\hline$u,_{e b b}(\mathrm{~m} / \mathrm{s})$ & -0.19 & -0.20 & -0.15 \\
\hline$v{ }_{e b b}(\mathrm{~m} / \mathrm{s})$ & $-7.81 e-16$ & $-2.28 \mathrm{e}-16$ & $5.81 \mathrm{e}-16$ \\
\hline$Q,_{e b b}\left(\mathrm{~m}^{3} / \mathrm{s}\right)$ & $-1.91 \mathrm{e}+06$ & $-3.10 \mathrm{e}+05$ & $-4.53 e+06$ \\
\hline$u,{ }_{\text {flood }}(\mathrm{m} / \mathrm{s})$ & -0.03 & -0.15 & -0.08 \\
\hline$v,{ }_{\text {flood }}(\mathrm{m} / \mathrm{s})$ & $7.24 \mathrm{e}-16$ & $7.22 \mathrm{e}-16$ & $-1.20 \mathrm{e}-16$ \\
\hline$Q,_{\text {flood }}\left(\mathrm{m}^{3} / \mathrm{s}\right)$ & $9.98 \mathrm{e}+04$ & $-6.59 \mathrm{e}+05$ & $-2.46 \mathrm{e}+06$ \\
\hline \multicolumn{4}{|c|}{ Mean normalized bias } \\
\hline$u,{ }_{e b b}(\mathrm{~m} / \mathrm{s})$ & -35.1 & -34.9 & -111.7 \\
\hline$v,_{e b b}(\mathrm{~m} / \mathrm{s})$ & 40.6 & -89.0 & -84.9 \\
\hline$Q,_{e b b}\left(\mathrm{~m}^{3} / \mathrm{s}\right)$ & -17.7 & 10.8 & -61.2 \\
\hline$u$, flood $(\mathrm{m} / \mathrm{s})$ & 8.14 & -73.8 & -14.9 \\
\hline$v,_{\text {flood }}(\mathrm{m} / \mathrm{s})$ & -73.0 & -179.9 & -73.2 \\
\hline$Q,_{e b b}\left(\mathrm{~m}^{3} / \mathrm{s}\right)$ & 2.08 & -30.5 & -26.0 \\
\hline \multicolumn{4}{|c|}{ Slope } \\
\hline$u,_{e b b}(\mathrm{~m} / \mathrm{s})$ & 0.99 & 1.69 & 0.69 \\
\hline$v,_{e b b}(\mathrm{~m} / \mathrm{s})$ & 1.04 & 2.57 & 0.75 \\
\hline$Q,_{e b b}\left(\mathrm{~m}^{3} / \mathrm{s}\right)$ & 0.81 & 1.58 & 0.52 \\
\hline$u,,_{\text {flood }}(\mathrm{m} / \mathrm{s})$ & 0.92 & 1.52 & -0.05 \\
\hline$v,{ }_{\text {flood }}(\mathrm{m} / \mathrm{s})$ & 0.95 & 0.79 & 1.43 \\
\hline$Q,_{\text {flood }}\left(\mathrm{m}^{3} / \mathrm{s}\right)$ & 0.55 & 1.14 & 0.04 \\
\hline \multicolumn{4}{|c|}{ Intercept } \\
\hline$u,{ }_{e b b}(\mathrm{~m} / \mathrm{s})$ & 0.19 & 0.08 & 0.19 \\
\hline$v,_{e b b}(\mathrm{~m} / \mathrm{s})$ & $8.10 \mathrm{e}-16$ & $-7.54 \mathrm{e}-16$ & $-6.46 e-16$ \\
\hline$Q,{ }_{e b b}\left(\mathrm{~m}^{3} / \mathrm{s}\right)$ & $4.04 \mathrm{e}+06$ & $5.39 \mathrm{e}+05$ & $7.03 \mathrm{e}+06$ \\
\hline$u,{ }_{\text {flood }}(\mathrm{m} / \mathrm{s})$ & 0.05 & 0.04 & 0.25 \\
\hline$v,{ }_{\text {flood }}(\mathrm{m} / \mathrm{s})$ & $-6.33 e-16$ & $5.57 \mathrm{e}-16$ & $3.30 \mathrm{e}-17$ \\
\hline$Q,_{\text {flood }}(\mathrm{m} 3 / \mathrm{s})$ & $4.39 \mathrm{e}+06$ & $-3.22 \mathrm{e}+05$ & $9.19 \mathrm{e}+06$ \\
\hline
\end{tabular}



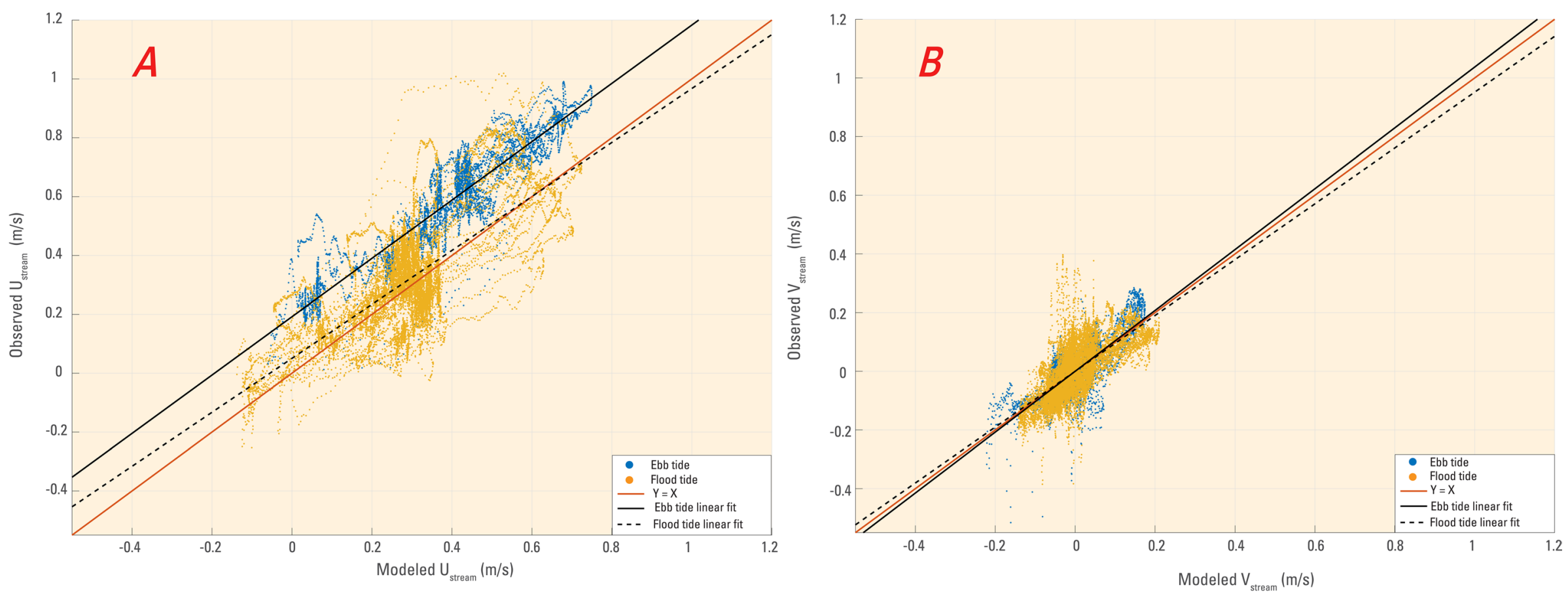

Figure 5. Scatter plots of $(A)$ trip 1 (blue dots) and trip 2 (yellow dots) modeled versus observed through-channel velocity in Mobile Bay Inlet. A line of $y=x$ (orange) is provided along with the lines of best fit for trip 1 (solid black) and trip 2 (dashed black). The $\mathrm{R}^{2}$ value associated with each linear fit is also given.

(B) Trip 1 (blue dots) and trip 2 (yellow dots) modeled versus observed V-velocity in Mobile Bay Inlet. A line of $y=x$ (orange) is provided along with the lines of best fit for trip 1 (solid black) and trip 2 (dashed black). The $R^{2}$ value associated with each linear fit is also given.

\section{Wave-Gage Comparison}

A single deterministic simulation was set up to span both wave-gage observation periods (2015/06/19 through 2015/11/20). The observation periods were consecutive and not overlapping. The 2015 DEM was used as the initial topobathymetric input. Sediment transport was computed, but the associated morphologic change was not. The simulation was set up to begin 6 hours before the start of observations.

The observed significant wave height, peak period, and direction associated with the peak period were compared with the model output on the fine wave grid at the grid points nearest the Aquadopp observation location (lat $30.242248^{\circ} \mathrm{N}$., long $88.2125^{\circ} \mathrm{W}$ ) near Katrina Cut and to the AWAC observation location $\left(30.200543^{\circ} \mathrm{N}\right.$., long $88.0927778^{\circ} \mathrm{W}$ ) near Pelican Island on the ebb tidal shoal. The linear fit and associated $\mathrm{R}^{2}$ value between the observed and fine-grid model predictions were calculated for the bulk wave characteristics of $H_{s}, T_{p}$, and $D_{p}$ for data from both observation periods (table 4). The time series of observed and modeled $H_{s}, T_{p}$, and $D_{p}$ at the Aquadopp and AWAC wave gages are shown in figures 7 and 8 , respectively. 

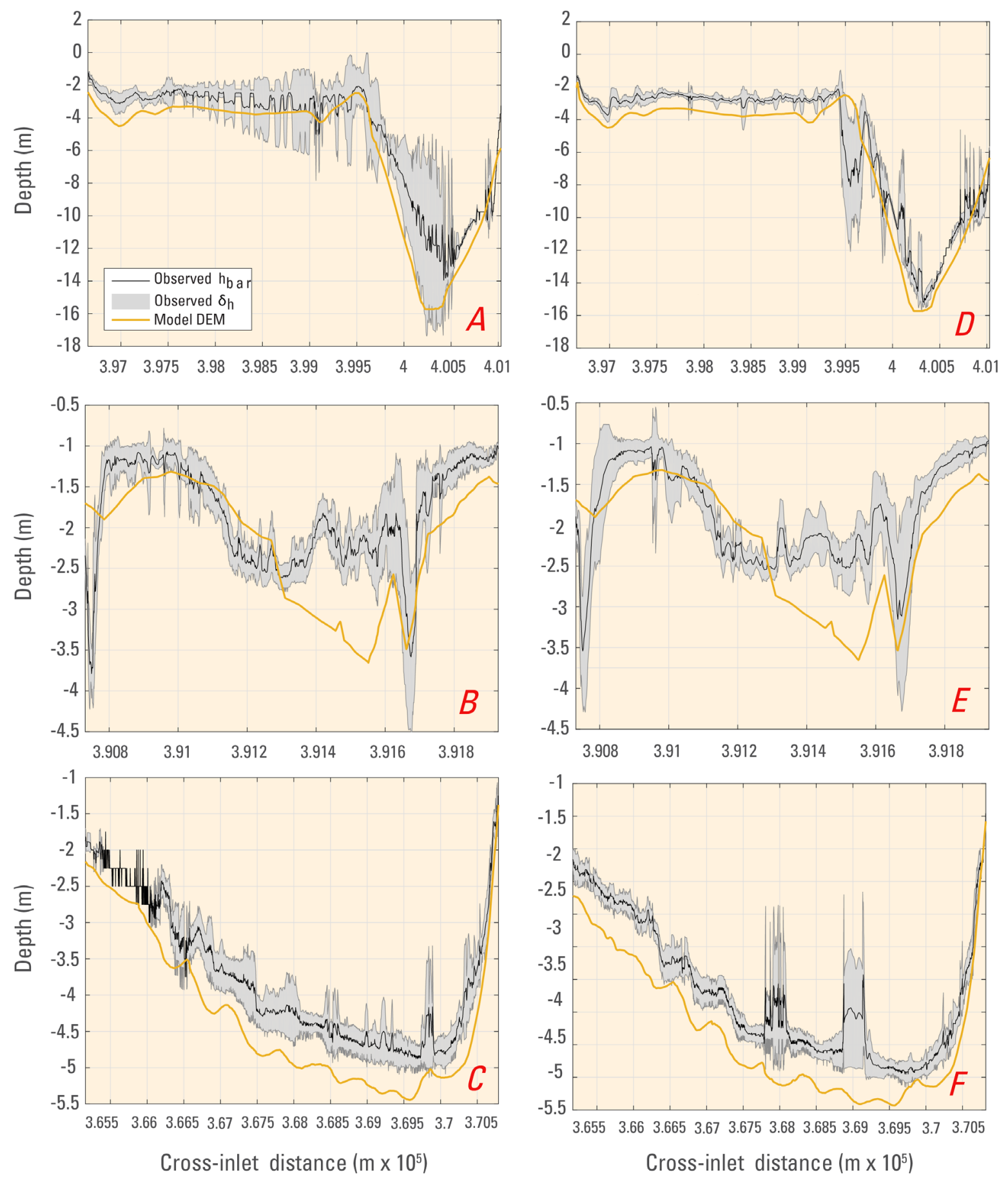

Figure 6. Graphs showing comparisons between observed depth and model digital elevation model (DEM) depths on all acoustic Doppler current profiler (ADCP) transects during trip 1 and trip 2. Panels $A, B$, and $C$ respectively show depth along the Mobile Bay Inlet, Pass Aux Herons, and Petit Bois Inlet observation transects, during trip 1. Panels $D, E$, and $F$ respectively show depth along the Mobile Bay Inlet, Pass Aux Herons, and Petit Bois Inlet observation transects, during trip 2. The mean observed depth is given by the solid black line while the standard deviation of those observed depths is shown by the grey shaded region. The model DEM depth interpolated to the observation transect is shown in yellow. 
$\mathrm{R}^{2}$ values show that the model is skilled in reproducing significant wave heights at both the Aquadopp and AWAC location and that the model skill is greater for the AWAC observation period. This observation is also shown for $H_{s}$ by the mean bias and normalized mean bias, which shows that the model underpredicts wave heights by roughly $8 \mathrm{~cm}$ and $11 \mathrm{~cm}$ at the AWAC and Aquadopp stations, respectively, or by about 3-8 percent - relative to the observed mean - as shown by the mean normalized bias. Overall, the model is relatively less skilled at reproducing peak periods and the direction of peak periods than it is at reproducing significant wave heights. The model error at the Aquadopp location may be partially due to the complicated and dynamic bathymetry near Katrina Cut, which would result in a poor comparison of model output using what could be rapidly outdated bathymetry to a single observation point. Offshore wave-forcing from WW3 compared well with observed wave heights at NDBC buoy 42012 with an $\mathrm{R}^{2}$ value of 0.81 , as shown in figure 9 . The winds used from WW3 also compared well with the observed winds at the buoy. However, the 6-hourly WW3 winds exclude the daily seabreeze and landbreeze cycles that could have influenced wave heights nearshore during the Aquadopp observation period of mid-June through late August, which would negatively impact model predictions.

A sensitivity test was carried out for this same simulation period to evaluate the sensitivity of the model to wind forcing. Model conditions and time periods were held constant with one modification: wind forcing was not applied to either the flow or wave domains, thereby replicating the wind conditions used in the mormerge applications. Statistics for this sensitivity study are given in table 5. A comparison between the case with forced winds and the case without wind forcing reveals reduced model skill in reproducing $H_{s}$ at both wave gage locations when winds are not applied. This difference is reflected by slightly lower $\mathrm{R}^{2}$ values and higher mean bias, mean normalized bias, and normalized RMSE values. Comparing the statistics of $\mathrm{R}^{2}$, mean bias, mean normalized bias, and normalized RMSE for $T_{p}$ show that the model skill in reproducing peak wave periods increases when winds are removed. The reduced model skill in reproducing $H_{s}$ when winds are removed suggests that the presence of winds improves the ability of the model to reproduce locally generated wind waves and bulk wave energy. Improved model skill in reproducing $T_{p}$ when wind forcing is removed suggests that the wave environment is primarily forced remotely (peak energy in higher period waves) and that the generation of wind-waves in the model can degrade the prediction of $T_{p}$ during bimodal wave-spectra time periods, when the model erroneously predicts more energy in the wind-wave band. 
Table 4. Coefficient of determination $\left(R^{2}\right)$, mean bias, mean normalized bias, root mean squared error (RMSE), and normalized RMSE statistics between observed and modeled significant wave height $\left(H_{s}\right)$, peak period $\left(T_{p}\right)$, average period $\left(T_{a}\right)$, direction (Dir), and average direction $\left(\operatorname{Dir}_{a}\right)$ at two nearshore wavegage stations.

[deg, degree; m, meter; \%, percent; s, second]

\begin{tabular}{|c|c|c|}
\hline Data field & AWAC & Aquadopp \\
\hline \multicolumn{3}{|c|}{$\mathrm{R}^{2}$} \\
\hline$H_{s}(\mathrm{~m})$ & 0.777 & 0.593 \\
\hline$T_{p}(\mathrm{~s})$ & 0.460 & 0.001 \\
\hline$T_{a}(\mathrm{~s})$ & 0.403 & 0.021 \\
\hline Dir (deg) & 0.203 & 0.177 \\
\hline $\operatorname{Dir}_{a}(\mathrm{deg})$ & 0.334 & 0.370 \\
\hline$H_{s}(\mathrm{~m})$ & -0.081 & -0.118 \\
\hline \multicolumn{3}{|c|}{ Mean Bias } \\
\hline$H_{s}(\mathrm{~m})$ & -0.081 & -0.118 \\
\hline$T_{p}(\mathrm{~s})$ & -0.352 & -1.024 \\
\hline$T_{a}(\mathrm{~s})$ & -1.022 & -0.932 \\
\hline $\operatorname{Dir}(\mathrm{deg})$ & -18.19 & 18.88 \\
\hline $\operatorname{Dir}_{a}(\mathrm{deg})$ & -14.03 & 19.95 \\
\hline$H_{s}(\mathrm{~m})$ & -0.081 & -0.118 \\
\hline \multicolumn{3}{|c|}{ Mean normalized bias } \\
\hline$H_{s}(\mathrm{~m})$ & -3.010 & -8.457 \\
\hline$T_{p}(\mathrm{~s})$ & -4.671 & -13.88 \\
\hline$T_{a}(\mathrm{~s})$ & -27.63 & -35.90 \\
\hline $\operatorname{Dir}(\operatorname{deg})$ & 12.27 & 88.64 \\
\hline $\operatorname{Dir}_{a}(\mathrm{deg})$ & 151.3 & 201.31 \\
\hline$H_{s}(\mathrm{~m})$ & -3.010 & -8.457 \\
\hline \multicolumn{3}{|c|}{ RMSE } \\
\hline$H_{s}(\mathrm{~m})$ & 0.196 & 0.174 \\
\hline$T_{p}(\mathrm{~s})$ & 1.164 & 1.682 \\
\hline$T_{a}(\mathrm{~s})$ & 0.559 & 0.552 \\
\hline $\operatorname{Dir}(\mathrm{deg})$ & 51.66 & 26.40 \\
\hline $\operatorname{Dir}_{a}(\mathrm{deg})$ & 44.73 & 18.28 \\
\hline$H_{s}(\mathrm{~m})$ & 0.196 & 0.174 \\
\hline \multicolumn{3}{|c|}{ Normalized RMSE } \\
\hline$H_{s}(\mathrm{~m})$ & 0.316 & 0.373 \\
\hline$T_{p}(\mathrm{~s})$ & 0.235 & 0.354 \\
\hline$T_{a}(\mathrm{~s})$ & 0.149 & 0.171 \\
\hline $\operatorname{Dir}(\mathrm{deg})$ & 0.316 & 0.153 \\
\hline $\operatorname{Dir}_{a}(\mathrm{deg})$ & 0.281 & 0.110 \\
\hline$H_{s}(\mathrm{~m})$ & 0.316 & 0.373 \\
\hline
\end{tabular}


Table 5. Results of a sensitivity test to wind forcing. $R^{2}$, mean bias, mean normalized bias, root mean squared error (RMSE) and normalized RMSE statistics for linear fits of observed and modeled significant wave height $\left(H_{s}\right)$, peak period $\left(T_{p}\right)$, average period $\left(T_{a}\right)$, direction (Dir), and average direction $\left(\right.$ Dir $\left._{a}\right)$ at two nearshore wave-gage stations for simulations in which wind forcing was not applied.

[deg, degree; m, meter; \%, percent; s, second]

\begin{tabular}{|c|c|c|}
\hline Data field & AWAC & Aquadopp \\
\hline \multicolumn{3}{|c|}{$\mathrm{R}^{2}$} \\
\hline$H_{s}(\mathrm{~m})$ & 0.708 & 0.567 \\
\hline$T_{p}(\mathrm{~s})$ & 0.490 & 0.024 \\
\hline$T_{a}(\mathrm{~s})$ & 0.525 & 0.108 \\
\hline Dir (deg) & 0.163 & 0.432 \\
\hline $\operatorname{Dir}_{a}(\mathrm{deg})$ & 0.247 & 0.235 \\
\hline$H_{s}(\mathrm{~m})$ & 0.708 & 0.567 \\
\hline \multicolumn{3}{|c|}{ Mean Bias } \\
\hline$H_{s}(\mathrm{~m})$ & -0.217 & -0.206 \\
\hline$T_{p}(\mathrm{~s})$ & -0.084 & -0.849 \\
\hline$T_{a}(\mathrm{~s})$ & -0.212 & -0.275 \\
\hline $\operatorname{Dir}(\mathrm{deg})$ & 0.656 & 12.27 \\
\hline $\operatorname{Dir}_{a}(\mathrm{deg})$ & 4.683 & 13.33 \\
\hline$H_{s}(\mathrm{~m})$ & -0.217 & -0.206 \\
\hline \multicolumn{3}{|c|}{ Mean normalized bias } \\
\hline$H_{s}(\mathrm{~m})$ & -34.21 & -32.27 \\
\hline$T_{p}(\mathrm{~s})$ & 2.156 & -10.44 \\
\hline$T_{a}(\mathrm{~s})$ & -6.253 & -17.92 \\
\hline Dir (deg) & 53.01 & 81.26 \\
\hline $\operatorname{Dir}_{a}(\mathrm{deg})$ & 145.9 & 184.9 \\
\hline$H_{s}(\mathrm{~m})$ & -34.21 & -32.27 \\
\hline \multicolumn{3}{|c|}{ RMSE } \\
\hline$H_{s}(\mathrm{~m})$ & 0.224 & 0.179 \\
\hline$T_{p}(\mathrm{~s})$ & 1.132 & 1.663 \\
\hline$T_{a}(\mathrm{~s})$ & 0.499 & 0.527 \\
\hline Dir (deg) & 52.83 & 25.45 \\
\hline$D i r_{a}(\mathrm{deg})$ & 47.56 & 17.36 \\
\hline$H_{s}(\mathrm{~m})$ & 0.224 & 0.179 \\
\hline \multicolumn{3}{|c|}{ Normalized RMSE } \\
\hline$H_{s}(\mathrm{~m})$ & 0.361 & 0.384 \\
\hline$T_{p}(\mathrm{~s})$ & 0.228 & 0.350 \\
\hline$T_{a}(\mathrm{~s})$ & 0.133 & 0.163 \\
\hline $\operatorname{Dir}(\mathrm{deg})$ & 0.324 & 0.147 \\
\hline $\operatorname{Dir}_{a}(\mathrm{deg})$ & 0.299 & 0.101 \\
\hline$H_{\mathrm{s}}(\mathrm{m})$ & 0.361 & 0.384 \\
\hline
\end{tabular}



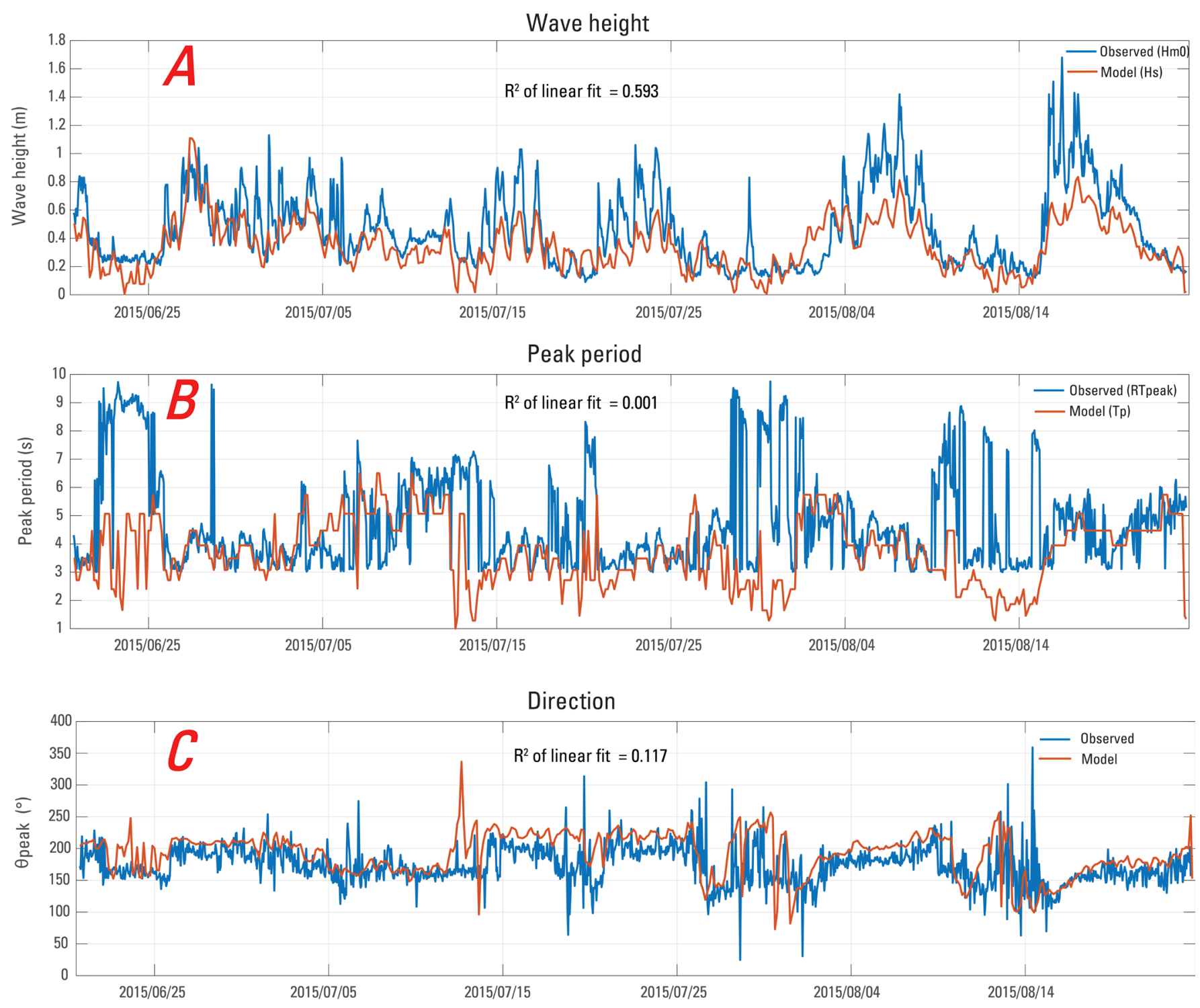

Figure 7. Time series graphs showing observed and modeled wave variables at the Aquadopp wave gage. $(A)$ Modeled significant wave height $\left(H_{s}\right)$ (orange line) and observed zeroth-moment wave height $(H m 0)$ (blue line). The comparison is presented with an associated coefficient of determination $\left(\mathrm{R}^{2}\right)$, in which $R^{2}=0.593$. (B) Observed and modeled peak period $\left(T_{p}\right)$ (blue line and orange line, respectively). The comparison is presented with an associated $R^{2}=0.001$. (C) Observed and modeled direction of the peak waves $\left(\theta_{\text {peak }}\right)$ (blue line and orange line, respectively). The comparison is presented with an associated $R^{2}=0.177$. 

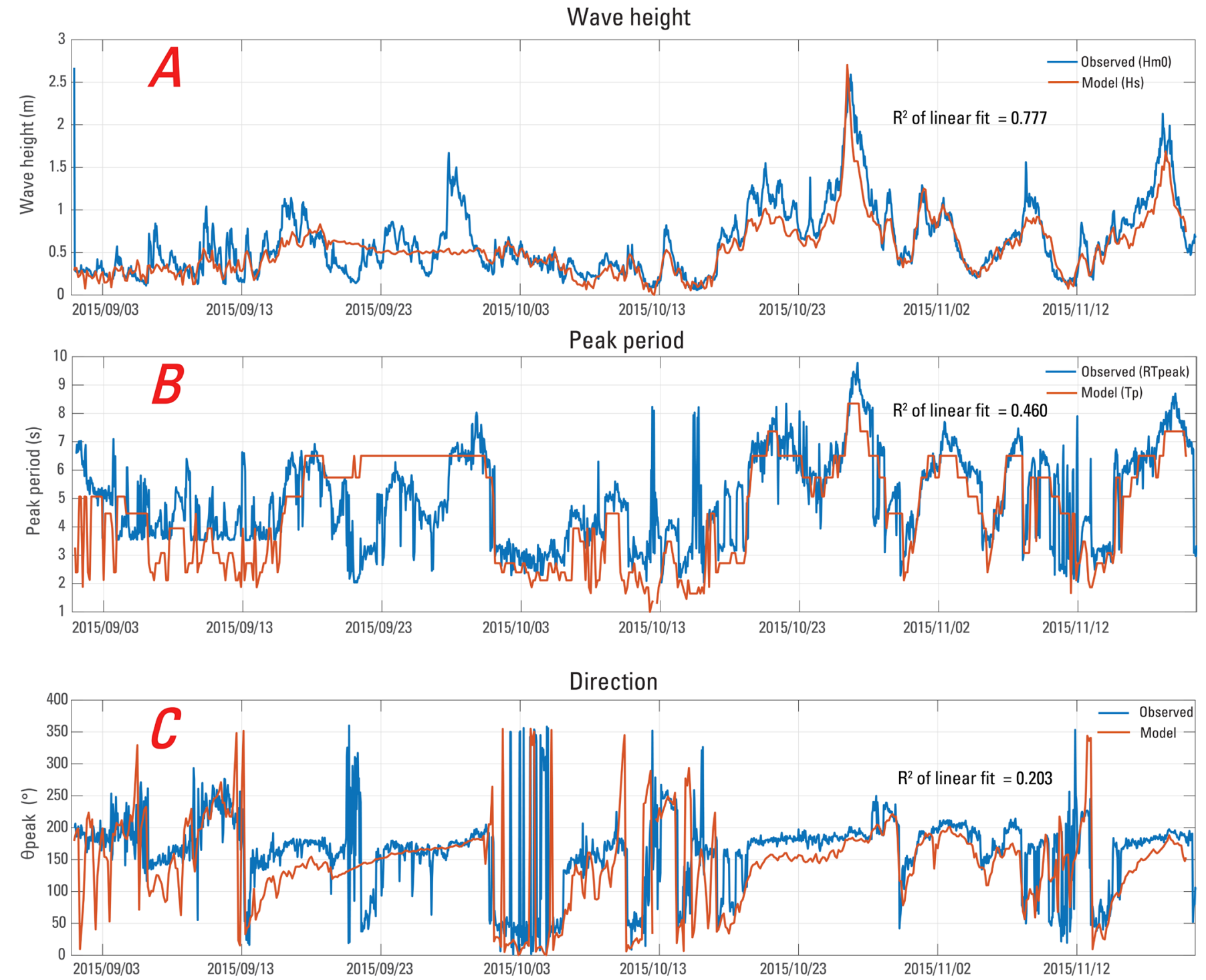

Figure 8. Time series graphs showing observed and modeled wave variables at the acoustic wave and current sensor (AWAC) wave gage. (A) Modeled significant wave height $\left(H_{s}\right)$ (orange line) and observed zeroth-moment wave height $(\mathrm{HmO})$ (blue line). The comparison is presented with an associated coefficient of determination $\left(R^{2}\right)$, in which $R^{2}=0.777$. (B) Observed and modeled peak period $\left(T_{p}\right)$ (blue line and orange line, respectively). The comparison is presented with an associated $R^{2}=0.460$. (C) Observed and modeled direction of the peak waves $\left(\theta_{\text {peak }}\right)$ (blue line and orange line, respectively). The comparison is presented with an associated $R^{2}=0.203$. 

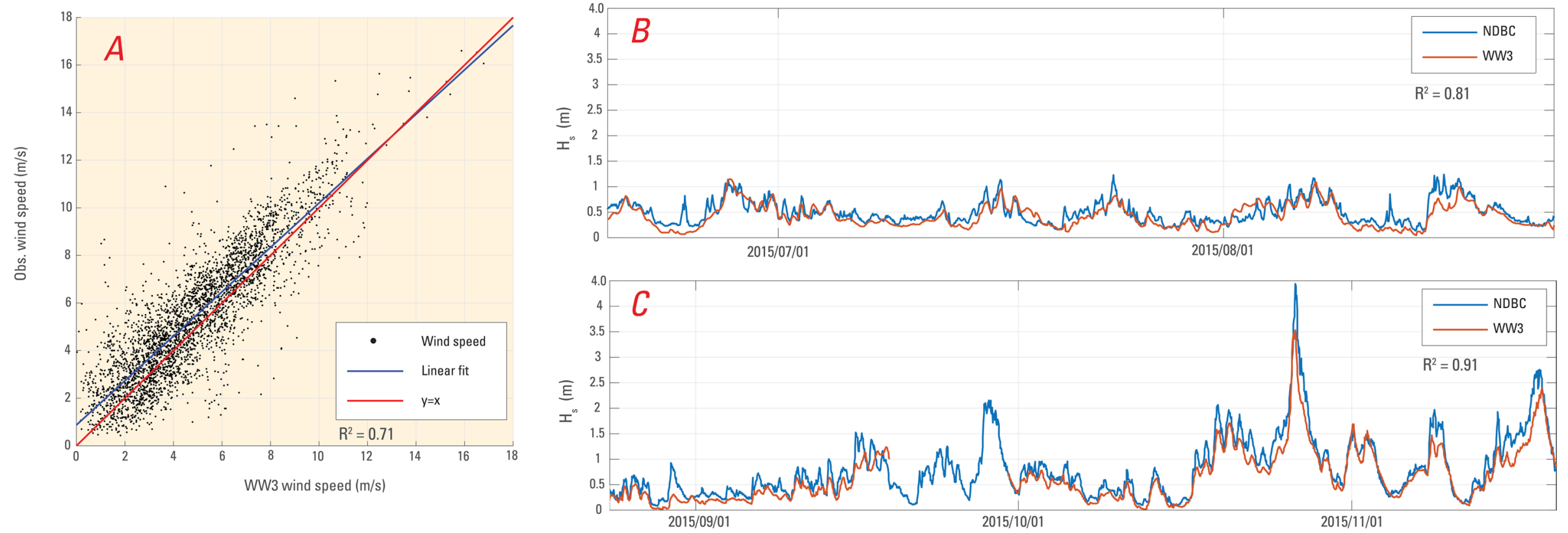

Figure 9. Graphs showing a comparison between WaveWatch III (WW3) wind and wave height forcing and observed winds and wave heights at National Data Buoy Center (NDBC) 42012. (A) Scatter plot of wind speeds (black dots) with a line of best fit (blue) and a line of $y=x$ (red). The comparison is presented with an associated coefficient of determination $\left(R^{2}\right)$ of 0.71 . $(B)$ time series of WW3 and observed significant wave height $\left(H_{s}\right)$ at NDBC 42012 for the Aquadopp observation period and is presented with an associated $R^{2}=0.81$. (C) Time series of WW3 and observed $H_{s}$ at NDBC 42012 for the acoustic wave and current sensor (AWAC) observation period and is presented with an associated $R^{2}=0.91$.

\section{Tide-Gage Validation}

The wave-gage validation simulation period of 2015/06/19 through 2015/11/20 discussed in the previous section also provided a 6-month time series of simulated water levels. Modeled water levels were taken from the flow grid output at the grid point near the Dauphin Island tide gage 8735180 (lat $30.250^{\circ}$ N., long $88.075^{\circ}$ W.) and compared with observed water levels at this station. Figure 10 illustrates the agreement $(\mathrm{R} 2=0.68)$ between the modeled and observed water levels at the Dauphin Island tide gage. The bias-corrected HYCOM water-level forcing applied at the offshore boundary was also compared with observations at the tide gage (fig. 4) and produced an $\mathrm{R}^{2}$ value of 0.87 . The degraded $\mathrm{D} 3 \mathrm{D}$ model error in reproducing water levels may be due in part to inaccuracies in the water-level boundary forcing, particularly inaccuracies in the phase of certain harmonic constituents.

A classical tidal-harmonic analysis was applied to both the observed water levels and the water-level forcing at the Dauphin Island tide gage, using the methods described in Pawlowicz and others (2002). The results of this analysis are given in table 6, as "significance," "amplitude," and "phase" for each harmonic constituent. A constituent is considered "significant" if the ratio of the squared root of the amplitude to error is less than 1 , 
which serves to separate tidal signals from noise. The results reveal discrepancies in the phase of $80^{\circ}$ to $200^{\circ}$ between the water-level forcing and observed water levels for certain nonlinear and shallow water harmonic tide-constituents. The individual amplitudes of the applied $M K 3, S K 3, M 4, M N 4$, MS4, M6 and 2SM6 constituents are small, with none exceeding 1 millimeter ( $\mathrm{mm}$ ); however, the sum of these amplitudes is equal to 16 percent of the fourth largest applied amplitude $(Q 1)$ and 4 percent of the largest applied amplitude $(\mathrm{Ol})$. Modeled water levels also do not reach the same peak during a storm which occurred during this period, consistent with an underprediction of a storm peak water level in the HYCOM water-level boundary forcing (fig. 4B). Underprediction of modeled water levels is quantified by a mean bias of $-1.72 \mathrm{e}-04 \mathrm{~m}$ and a mean normalized bias of -11.78 percent. Some error in reproducing water levels may be due to the absence of time-dependent water-level forcing at the lateral boundaries, where only a Neumann boundary condition is applied. Finally, a portion of the error may be due to an imperfect location match between the in situ tide gage, which is on a tower near to land at the end of a pier and the observation location, by constraints of the model grid not being so close to shore, may mean there is some difference in the water depth at the tide gage and the water depth of the model point used. 
Table 6. Results of a classical tidal harmonic analysis of the applied water-level forcing (HYCOM) and the observed water levels at station 8735180 . Results of the modeled output near the water-level station are also included. Only those harmonic constituents that were found to be significant for at least one of the tide datasets (applied, observed, or modeled) are presented. Tidal harmonic amplitudes and phases are given for each significant harmonic constituent. In this analysis, a constituent is said to be significant if the square ratio of its amplitude to the error in amplitude is less than 1.

$[\mathrm{m}$, meter]

\begin{tabular}{|c|c|c|c|c|c|c|c|c|c|c|}
\hline \multicolumn{2}{|c|}{ Constituent } & \multicolumn{3}{|c|}{ Significant } & \multicolumn{3}{|c|}{ Amplitude (m) } & \multicolumn{3}{|c|}{ Phase (degrees) } \\
\hline & & HYCOM & Observed & Modeled & HYCOM & Observed & Modeled & HYCOM & Observed & Modeled \\
\hline$Q 1$ & $\begin{array}{l}\text { Large lunar elliptic } \\
\text { diurnal }\end{array}$ & Yes & Yes & Yes & 0.0218 & 0.0257 & 0.0189 & 21.20 & 30.43 & 53.82 \\
\hline$O 1$ & Lunar diurnal & Yes & Yes & Yes & 0.0942 & 0.1049 & 0.0984 & 37.60 & 35.80 & 68.76 \\
\hline K1 & Lunar diurnal & Yes & Yes & Yes & 0.0893 & 0.1106 & 0.0975 & 43.07 & 45.85 & 72.40 \\
\hline N2 & $\begin{array}{l}\text { Larger lunar elliptic } \\
\text { semidiurnal }\end{array}$ & Yes & -- & -- & 0.0051 & 0.0032 & 0.0024 & 136.92 & 154.91 & 231.91 \\
\hline M2 & $\begin{array}{r}\text { Principal lunar } \\
\text { semidiurnal }\end{array}$ & Yes & Yes & Yes & 0.0224 & 0.0178 & 0.0186 & 129.42 & 139.73 & 208.99 \\
\hline$S 2$ & $\begin{array}{r}\text { Principal solar } \\
\text { semidiurnal }\end{array}$ & Yes & Yes & Yes & 0.0127 & 0.0085 & 0.0088 & 113.28 & 123.80 & 216.80 \\
\hline$M O 3$ & ----------- & Yes & Yes & Yes & 0.0008 & 0.0021 & 0.0020 & 264.71 & 149.30 & 313.36 \\
\hline$M K 3$ & $\begin{array}{l}\text { Shallow water } \\
\text { terdiurnal }\end{array}$ & Yes & -- & Yes & 0.0010 & 0.0008 & 0.0019 & 278.32 & 142.76 & 297.88 \\
\hline$S K 3$ & Compound tide & Yes & -- & Yes & 0.0007 & 0.0011 & 0.0014 & 294.98 & 213.84 & 333.38 \\
\hline M4 & $\begin{array}{l}\text { Shallow water } \\
\text { overtides of } \\
\text { principal lunar }\end{array}$ & -- & Yes & -- & 0.0003 & 0.0037 & 0.0001 & 76.86 & 352.78 & 327.36 \\
\hline MN4 & $\begin{array}{l}\text { Shallow water } \\
\text { quarter diurnal }\end{array}$ & -- & Yes & -- & 0.0003 & 0.0019 & 0.0002 & 111.78 & 308.99 & 10.06 \\
\hline MS4 & $\begin{array}{l}\text { Shallow water } \\
\text { quarter diurnal }\end{array}$ & Yes & -- & Yes & 0.0007 & 0.0007 & 0.0008 & 120.78 & 39.42 & 151.27 \\
\hline M6 & $\begin{array}{l}\text { Shallow water } \\
\text { overtides of } \\
\text { principal lunar }\end{array}$ & Yes & -- & -- & 0.0003 & 0.0006 & 0.0001 & 269.81 & 67.11 & 191.22 \\
\hline $2 S M 6$ & 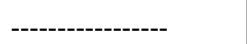 & -- & -- & Yes & 0.0001 & 0.0005 & 0.0002 & 245.68 & 42.60 & 197.91 \\
\hline
\end{tabular}



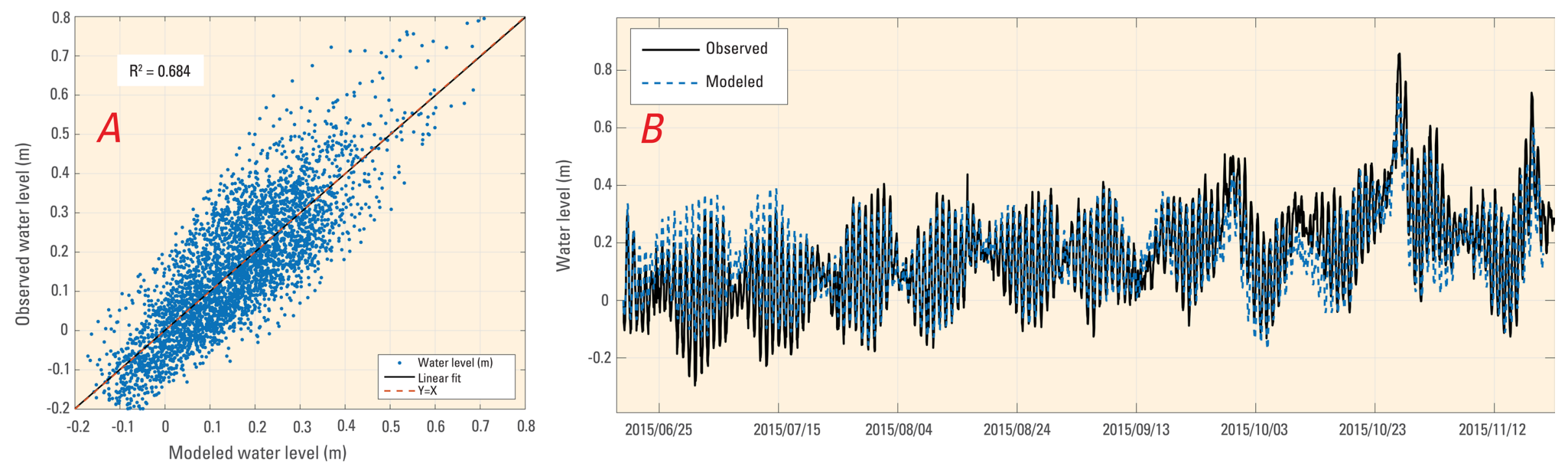

Figure 10. Graphs showing modeled and and observed water levels. (A) Scatter plot of modeled and observed water levels at station 8735180 (blue dots). The line of best fit is given (black line) as well as a line of $y=x$ (dashed orange line). The coefficient of determination $\left(R^{2}\right)$ of the linear fit is also provided and is equal to 0.68. (B) Time series comparison between modeled and observed water levels at the Dauphin Island tide gage for the same period. The mean bias between observed and modeled water levels is equal to $-1.72 \mathrm{e}-04$ meters $(\mathrm{m})$, while the mean normalized bias is equal to -11.78 percent.

\section{Comparison to Observations: Mormerge Simulations}

\section{Lidar Shoreline Validation}

A mormerge simulation was set up in D3D to simulate littoral sediment transport and island morphological conditions over longer temporal scales. The model setup used the post-storm 2005 DEM as the topobathymetric input. Water-level forcing was supplied by harmonic morphological tides at the southern open boundary. The wave parameters of each mormerge scenario (table 1) were used to generate a JONSWAP spectra applied at the offshore boundary. The simulation period, September 2005 through June 2007, captured a quiescent period with no tropical storms affecting Dauphin Island that would require the use of a storm model (for example, XBeach in Roelvink and others, 2009). The simulation began 6 hours prior to the start of the morphological change to allow for the spin-up of model sediment transport to a quasi-steady state driven by water levels, water velocities, and waves.

Observed shorelines are defined by the 24-cm MHW position. For comparison between modeled and observed lidar shoreline-change rates, the zero-meter contour of the modeled depth was extracted. Modeled depths at each output time were first interpolated onto an array of cross-shore transects spaced $100 \mathrm{~m}$ apart along Dauphin Island (Hendersen and others, 2017). The zero crossing of modeled depth from subaerial to subaqueous was then located on each transect for each output time to create a time series of modeled shoreline positions, from which 
a shoreline linear regression rate (LRR,) in meters per year, was calculated for each transect. Similarly, observed LRRs were calculated from the observed MHW shoreline position on each transect. Separate bulk $\mathrm{R}^{2}$ values were calculated between modeled and observed LRRs for all east-end (east of Katrina Cut) and west-end transects (west of Katrina Cut), as well as for the five sub-segments ( $A, B, C, D$, and $E$ ) delineated in figure 11, along with the additional error statistics (table 7). Lidar data showed that some isolated breaches in the island were not captured well in the initial model DEM due to the alongshore grid-spacing. No comparison was made at locations where there were discrepancies between the initial observed-shoreline model DEM.

The overall $\mathrm{R}^{2}$ values show that the model is more skilled at reproducing littoral sediment transport on the west end of the island $\left(\mathrm{R}^{2}=0.12\right)$ than on the island's east end $\left(\mathrm{R}^{2}=0.001\right)$. Region $A$ on figure 11 compares observed and modeled LRRs and shows qualitative agreement between observed and modeled LRRs on the west end, lending confidence to model skill at reproducing convergent and divergent transport patterns over this region. Regions of $B$ and $D$ in figure 11 also highlight model skill in reproducing general LRR trends for those transects in highly variable and rapidly evolving areas near Katrina Cut and Pelican Island, although at relatively less skill than in region $A$. Both observed and modeled LRR show little evolution on transects in region $E$ of figure 11. Observed shorelines accreted much faster over a number of east-end transects that were affected by anthropogenic influences. Specifically, in region $C$ of figure 11, was the placement of a 0.382 million cubic meters $\left(\mathrm{m}^{3}\right)$ Federal Emergency Management Agency sand berm constructed between January and June 2007 that was not accounted for in the model. The footprint of this sand berm design was such that its shoreline was farther offshore than the initial shoreline used in the model. Additional model error in predicting LRRs are likely due to a mismatch between real bathymetric conditions at the beginning of the simulation period and the model DEM used. 
Table 7. Coefficient of determination $\left(R^{2}\right)$, mean bias, mean normalized bias, root mean square error (RMSE) and normalized RMSE statistics between observed and modeled shoreline linear regression rates by island segment. Segments $(A, B, C, D$, and $E)$ are delineated in figure 11 and do not necessarily contain the same number of transects.

[m/yr, meters per year; \%, percent]

\begin{tabular}{|c|c|}
\hline \multicolumn{2}{|c|}{ Map segment } \\
\hline \multicolumn{2}{|c|}{$\mathrm{R}^{2}$} \\
\hline$A$ & 0.102 \\
\hline$B$ & 0.198 \\
\hline C & 0.287 \\
\hline$D$ & 0.006 \\
\hline$E$ & 0.005 \\
\hline \multicolumn{2}{|c|}{ Mean bias (m/yr) } \\
\hline$A$ & 4.452 \\
\hline$B$ & 7.679 \\
\hline C & -12.63 \\
\hline$D$ & 17.54 \\
\hline$E$ & -0.080 \\
\hline \multicolumn{2}{|c|}{ Mean normalized bias } \\
\hline A & -40.16 \\
\hline$B$ & -57.48 \\
\hline C & -84.25 \\
\hline$D$ & -133.2 \\
\hline$E$ & -176.3 \\
\hline \multicolumn{2}{|c|}{ RMSE (m/yr) } \\
\hline$A$ & 10.92 \\
\hline$B$ & 15.468 \\
\hline C & 5.539 \\
\hline$D$ & 8.543 \\
\hline$E$ & 7.904 \\
\hline \multicolumn{2}{|c|}{ Normalized RMSE } \\
\hline$A$ & 0.483 \\
\hline$B$ & 0.463 \\
\hline C & 0.420 \\
\hline$D$ & 4.815 \\
\hline E & 2.558 \\
\hline
\end{tabular}



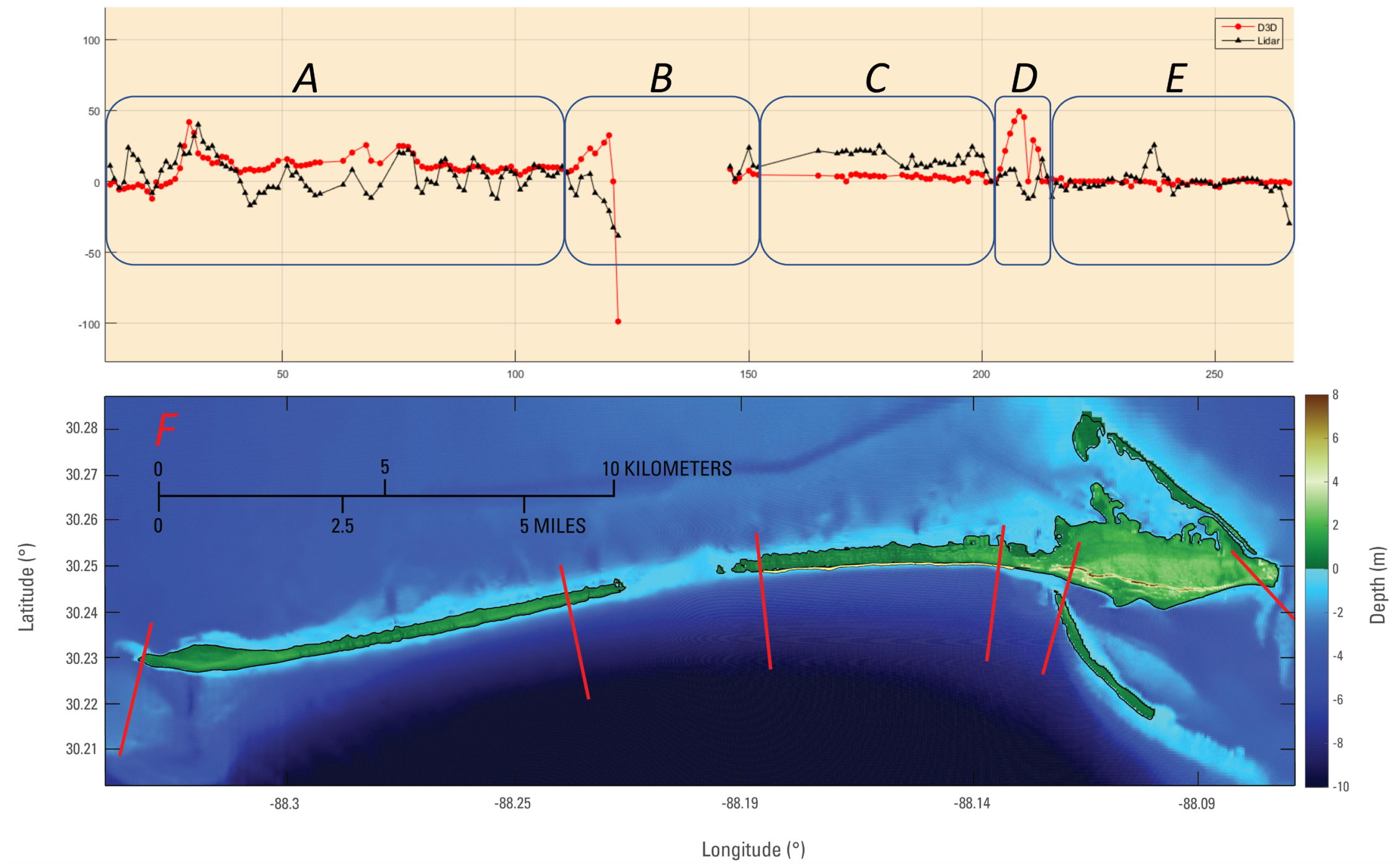

Figure 11. Graph and map showing observed and modeled shoreline linear regression rates for the period of 2005-2007 (A-E) shown alongside $(F)$ Dauphin Island digital elevation model (DEM). Vertical red lines indicate bounds of regions $A, B, C, D$, and $E$. Regions $A, B, D$, and $E$ show that overall shoreline regression rates are fairly well-modeled during this period. Region $E$ shows agreement with little change East of Pelican Island, while region $D$ shows that the model captures impacts of Pelican Island. Region $B$ illustrates that the evolution of Katrina Cut is also represented, while region $A$ also shows that the general linear regression rate (LRR) trends are captured by the model. Region $C$ shows a significant and consistent offset between modeled and observed LRR. In region C, a sand berm (yellow region on F) was built in 2007 that was not included in the model, resulting in this offset. 


\section{Conclusions}

A modeling system was developed to simulate the littoral sediment transport along Dauphin Island, Alabama, using the Delft3D (D3D) FLOW and WAVE and "mormerge" configurations. A deterministic application of the modeling system was implemented, and three simulations were run to coincide with two periods of observations of circulation (ebb and flood tide during summer and winter, respectively) and two periods of wave observation (back-to-back summer period). The comparison between modeled and observed water velocities and volumetric flow rates through inlets showed that the model skill was greatest in Mobile Bay Inlet during the dominant ebb tide and less skilled in Pass Aux Herons and Petit Bois Inlet. Additionally, it was shown that model skill was greater for predicting the dominant through-channel velocity than for the weaker cross-channel velocity. Lesser model skill in Pass Aux Herons and Petit Bois Inlet is likely due to the lower north-south grid resolution across this inlet and inaccurate, outdated initial bathymetry. The expectation, however, is that Mobile Bay Inlet has the largest influence on the evolution of Dauphin Island.

A comparison of the model output to the wave-gage data indicated that the model predicted wave propagation to the island and was generally limited by the skill of the WW3 wave data applied at the boundaries (fig. 9). The model reproduced wave characteristics better on the ebb tidal shoal than in front of the rock wall constructed after a previous breach in the island, likely due to the complex and potentially dynamic bathymetry at the latter location. Further reduction in model skill may result from the seabreeze and land-breeze cycles observed during the observation period that were absent in the applied wind forcing. Comparisons between modeled and observed water levels for a 6-month period show strong model skill.

A statistical mormerge application of the modeling system was implemented, for a single simulation, to model alongshore littoral sediment transport. Comparisons between the observed and modeled shoreline position linear-regression rates showed that the model was skilled in capturing overall trends in shoreline linear-regression rates along Dauphin Island, which served as a proxy for alongshore littoral sediment transport. The region for which the model had the lowest predictive skill corresponded to an area of sand berm construction that was not incorporated into the model. These comparisons to both hydrodynamic and morphological observations suggest that the modeling system can characterize the littoral sediment transport along Dauphin Island, Alabama. 


\section{References Cited}

Benedet, L., Dobrochinski, J.P.F., Walstra, D.J.R., Klein, A.H.F., and Ranasinghe, R., 2016, A morphological modeling study to compare different methods of wave climate schematization and evaluate strategies to reduce erosion losses from a beach nourishment project: Coastal Engineering, v. 112, June, p. 69-86, accessed May 12, 2018, at https://doi. org/10.1016/j.coastaleng.2016.02.005.

Bleck, R., 2002, An oceanic general circulation model framed in hybrid isopycnic-cartesian coordinates: Ocean Modeling, v. 4, no. 1, p. 55-88. [Also available at https://doi.org/10.1016/ s1463-5003(01)00012-9.]

Booij, N., Ris, R.C., and Holthuijsen, L.H., 1999, A third-generation wave model for coastal regions-1. Model description and validation: Journal of Geophysical Research-Oceans, v. 104, no. C4, p. 7649-7666. [Also available at https://doi.org/10.1029/98jc02622.]

Danielson, J.J., Brock, J.C., Howard, D.M., Gesch, D.B., Bonisteel-Cormier, J.M., and Travers, L.J., 2013, Topobathymetric model of Mobile Bay, Alabama: U.S. Geological Survey Data Series 769, accessed October 1, 2017, at https://doi.org/10.3133/ds769/.

Dee, D.P. and others, 2011, The ERA-Interim reanalysis: configuration and performance of the data assimilation system: Quarterly Journal of the Royal Meteorological Society, v. 137, no. 656, p. 553-597. [Also available at https://doi.org/10.1002/qj.828.]

Deltares, 2018a, Delft3D-FLOW user manual version 3.15, SVN revision 61637: Delft, The Netherlands, Deltares, 682 p., accessed June 6, 2018, at https://content.oss.deltares.nl/delft3d/manuals/ Delft3D-FLOW_User_Manual.pdf.

Deltares, 2018b, Delft3D-WAVE user manual version 3.05, SVN revision 58426: Delft, The Netherlands, Deltares, 200 p., accessed June 6, 2018, at https://content.oss.deltares.nl/delft3d/manuals/ Delft3D-WAVE_User_Manual.pdf.

DeWitt, N.T., Stalk, C.A., Flocks, J.G., Bernier, J.C., Kelso, K.W., Fredericks, J.J., and Tuten, T., 2017, Single-beam bathymetry data collected in 2015 nearshore Dauphin Island, Alabama: U.S. Geological Survey data release, accessed August 8, 2016, at https://doi.org/10.5066/F7BZ648W.

Ellis, A.M., Marot, M.E., Smith, C.G., and Wheaton, C.J., 2017, The physical characteristics of the sediments on and surrounding Dauphin Island, Alabama: U.S. Geological Survey Data Series 1046, accessed September 22, 2018, at https://doi.org/10.3133/ds1046.

Flocks, J.G., DeWitt, N.T., and Stalk, C.A., 2017, Analysis of seafloor change at Dauphin Island, Alabama, 1987-2015: U.S. Geological Survey Open-File Report 2017-1112, 19 p., accessed August 11, 2016, at https://doi.org/10.3133/ofr20171112.

Hasselmann, K., Barnett, T.P., Bouws, E., Carlson, H., Cartwright, D.E., Enke, K., Ewing, J.A., Gienapp, H., Hasselmann, D.E., Kruseman, P., Meerburg, A., Müller, P., Olbers, D.J., Richter, K., Sell, W., and Walden, H., 1973. Measurements of wind-wave growth and swell decay during the Joint North Sea Wave Project (JONSWAP): Deutsche Hydrographische Zeitschrift [German Hydrography Journal], Ergänzungsheft [Supplement], v. 8, no. 12.

Henderson, R.E, Nelson, P. R., Long, J.W., and Smith, C.G., 2017, Vector shorelines and associated shoreline change rates derived from lidar and aerial imagery for Dauphin Island, Alabama-1940-2015: U.S. Geological Survey data release, accessed December 4, 2015, at https:// doi.org/10.5066/F7T43RB5. 
Kranenburg, C.J., Long, J.W., and Zawada, D.G., 2016, EAARL coastal topography-Dauphin Island, post-Hurricane Katrina, 2005: U.S. Geological Survey data release, accessed December 19, 2016, at https://doi.org/10.5066/F78G8HSG.

Lesser, G.R., 2009, An approach to medium-term coastal morphological modelling: Delft, The Netherlands, Delft University of Technology, Ph.D. dissertation, 238 p. [Also available at https:// repository.tudelft.nl/assets/uuid:62caa573-4fc0-428e-8768-0aa47ab612a9/PHD_THESIS_ LESSER.pdf.]

Lesser, G.R., Roelvink, J.A., van Kester, J.A.T.M., and Stelling, G.S., 2004, Development and validation of a three-dimensional morphological model: Coastal Engineering, v. 51, nos. 8-9, p. 883-915, accessed December 19, 2016, at https://doi.org/10.1016/j.coastaleng.2004.07.014.

Long, J.W., Plant, N.G., Dalyander, P.S., and Thompson, D.M., 2014, A probabilistic method for constructing wave time-series at inshore locations using model scenarios: Coastal Engineering, v. 89, July, p. 53-62. [Also available at https://doi.org/10.1016/j.coastaleng.2014.03.008.]

National Data Buoy Center, 2017a, Station 42040: National Oceanic and Atmospheric Administration web page, accessed December 30, 2017, at https://www.ndbc.noaa.gov/station_page. php?station $=42040$.

National Data Buoy Center, 2017b, Station 42012: National Oceanic and Atmospheric Administration web page, accessed December 1, 2017, at https://www.ndbc.noaa.gov/station_page. php?station $=42012$.

National Oceanic and Atmospheric Administration [NOAA], 2009, Mobile, Alabama 1/3 MHW coastal digital elevation model: NOAA National Centers for Environmental Information web page, accessed December 1, 2017, at https://www.ngdc.noaa.gov/metaview/page?xml=NOAA/ NESDIS/NGDC/ MGG/DEM/iso/xml/673.xml\&view=getDataView\&header=none)/.

National Oceanic and Atmospheric Administration [NOAA], 2017, Dauphin Island, AL-Station ID_8735180: NOAA Tides and Currents web page, accessed November 1, 2017, at https:// tidesandcurrents.noaa.gov/stationhome.html?id=8735180.

Passeri, D.L., Long, J.W., Jenkins, R.L., Thompson, D.M., 2018a, Effects of proposed navigation channel improvements on sediment transport in Mobile Harbor, Alabama: U.S. Geological Survey Open-File Report 2018-1123, 22 p., accessed January 19, 2019, at https://doi.org/10.3133/ ofr20181123.

Passeri, D.L., Long, J.W., Plant, N.G., Bilskie, M.V., Hagen, S.C., 2018b, The influence of bed friction variability due to land cover on storm-driven barrier island morphodynamics: Coastal Engineering, v. 132, February, p.82-94, accessed December 22, 2018, at https://doi. org/10.1016/j.coastaleng.2017.11.005

Pawlowicz, R., Beardsley, B., and Lentz, S., 2002, Classical Tidal Harmonic Analysis Including Error Estimates in MATLAB using T_TIDE: Computers and Geosciences, v. 28, no. 8, p. 929-937, accessed May 30, 2019, at https://doi.org/10.1016/s0098-3004(02)00013-4.

Roelvink, D., Reniers, A., van Dongeren, A., van Thiel de Vries, J., McCall, R., and Lescinski, J., 2009, Modelling storm impacts on beaches, dunes and barrier islands: Coastal Engineering, v. 56, nos. 11-12, p. 1133-1152. [Also available at https://doi.org/10.1016/j.coastaleng.2009.08.006].

Thompson, D.M., Dalyander, P.S., Long, J.W., and Plant, N.G., 2017, Correction of elevation offsets in multiple co-located lidar datasets: U.S. Geological Survey Open-File Report 2017-1031, 10 p., accessed January 5, 2018, at https://doi.org/10.3133/ofr20171031. 
Tolman, H.L., 1989, The numerical model WAVEWATCH-A third generation model for the hindcasting of wind waves on tides in shelf seas: Communications on Hydraulic and Geotechnical Engineering, Delft University of Technology, Report 89-2, 72 p. [Also available at https://repository. tudelft.nl/islandora/object/uuid:5d12fc8b-6fa3-4c09-826c-d6955e1d33ab?collection=research.]

Walstra, D.J.R., Hoekstra, R., Tonnon, P.K., and Ruessink, B.G., 2013, Input reduction for longterm morphodynamic simulations in wave-dominated coastal settings: Coastal Engineering, v. 77, July, pp.57-70, accessed July 11, 2018, at https://doi.org/10.1016/j.coastaleng.2013.02.001.

\section{Appendix 1.}

In this appendix, the model inputs for the Delft 3D (D3D) model used in this study are defined. The model parameters and settings for the FLOW module for the deterministic applications are described in table 1.1, while table 1.2 lists the settings for the WAVE module. The model parameters and settings for the morphology for the deterministic applications are given in table 1.3. Tables 1.4, 1.5, and 1.6 provide the model parameters and settings for the FLOW, WAVE, and morphology, respectively, of the mormerge application. Note that in tables 1.4, 1.5, and 1.6, the duplicate parameters from 1.1, 1.2, and 1.3 are not given, and any parameter not presented in the latter three tables should be assumed identical to the former three. All parameters provided are relevant to D3D version number 4.00.01.

Table 1.1. Model parameter and settings for the FLOW portion of the deterministic applications as set in model master definition file (.mdf). Specific input file names for grid, initial dates, runtimes, enclosure, depth, friction, dry points, winds, boundary conditions, sediment, morphology, and observations are excluded.

\begin{tabular}{|l|l|}
\hline \multicolumn{2}{|c|}{ Master definition file input } \\
\hline Input name & \multicolumn{1}{c|}{ Value } \\
\hline Anglat & $3.0200000 \mathrm{e}+001$ \\
\hline Grdang & $0.0000000 \mathrm{e}+000$ \\
\hline MNKmax & 13696581 \\
\hline Thick & $1.0000000 \mathrm{e}+002$ \\
\hline Tunit & \#M\# \\
\hline Tstart & $0.0000000 \mathrm{e}+000$ \\
\hline Dt & 0.375 \\
\hline Tzone & 0 \\
\hline Sub1 & \# W \# \\
\hline Sub2 & \# CW\# \\
\hline Wnsvwp & \#Y\# \\
\hline Wndint & \#Y\# \\
\hline Zeta0 & $0.0000000 \mathrm{e}+000$ \\
\hline
\end{tabular}


Table 1.1. Model parameter and settings for the FLOW portion of the deterministic applications as set in model master definition file (.mdf). Specific input file names for grid, initial dates, runtimes, enclosure, depth, friction, dry points, winds, boundary conditions, sediment, morphology, and observations are excluded.-Continued

\begin{tabular}{|c|c|}
\hline \multicolumn{2}{|c|}{ Master definition file input } \\
\hline Input name & Value \\
\hline $\mathrm{C} 01$ & $0.0000000 \mathrm{e}+000$ \\
\hline Rettis & $0.0000000 \mathrm{e}+000$ \\
\hline Rettib & $0.0000000 \mathrm{e}+000$ \\
\hline $\mathrm{Ag}$ & $9.8100000 \mathrm{e}+000$ \\
\hline Rhow & $1.0000000 \mathrm{e}+003$ \\
\hline Tempw & $1.5000000 \mathrm{e}+001$ \\
\hline Salw & $3.1000000 \mathrm{e}+001$ \\
\hline Rouwav & \#FR84\# \\
\hline Wstres & $\begin{array}{c}6.3000000 \mathrm{e}-004 \\
0.0000000 \mathrm{e}+000 \\
7.2300000 \mathrm{e}-003 \\
3.0000000 \mathrm{e}+001 \\
7.2300000 \mathrm{e}-003 \\
3.0000000 \mathrm{e}+001 \\
\end{array}$ \\
\hline Rhoa & $1.0000000 \mathrm{e}+000$ \\
\hline Betac & $5.0000000 \mathrm{e}-001$ \\
\hline Equili & \#N\# \\
\hline Ktemp & 0 \\
\hline Fclou & $0.0000000 \mathrm{e}+000$ \\
\hline Sarea & $0.0000000 \mathrm{e}+000$ \\
\hline Temint & \#Y\# \\
\hline Roumet & \#C\# \\
\hline Xlo & $0.0000000 \mathrm{e}+000$ \\
\hline Vicouv & $1.0000000 \mathrm{e}+000$ \\
\hline Dicouv & $1.0000000 \mathrm{e}+000$ \\
\hline Htur2d & \#N\# \\
\hline Irov & 0 \\
\hline Iter & 2 \\
\hline Dryflp & \#YES\# \\
\hline Dpsopt & \#DP\# \\
\hline
\end{tabular}


Table 1.1. Model parameter and settings for the FLOW portion of the deterministic applications as set in model master definition file (.mdf). Specific input file names for grid, initial dates, runtimes, enclosure, depth, friction, dry points, winds, boundary conditions, sediment, morphology, and observations are excluded.-Continued

\begin{tabular}{|c|c|}
\hline \multicolumn{2}{|c|}{ Master definition file input } \\
\hline Input name & Value \\
\hline Dpuopt & \#MOR\# \\
\hline Dryflc & $1.0000000 \mathrm{e}-001$ \\
\hline Dco & $-9.9900000 e+002$ \\
\hline Tlfsmo & $6.0000000 \mathrm{e}+001$ \\
\hline ThetQH & $0.0000000 \mathrm{e}+000$ \\
\hline Forfuv & \#N\# \\
\hline Forfww & \#N\# \\
\hline Sigcor & $\# \mathrm{~N} \#$ \\
\hline Trasol & \#Cyclic-method\# \\
\hline Momsol & \#Cyclic\# \\
\hline SMhydr & \#YYYYY\# \\
\hline SMderv & \#YYYYYY\# \\
\hline SMproc & \#YYYYYYYYYY\# \\
\hline PMhydr & \#YYYYYY\# \\
\hline PMderv & \#YYY\# \\
\hline PMproc & \#YYYYYYYYYY\# \\
\hline SHhydr & \#YYYY\# \\
\hline SHderv & \#YYYYY\# \\
\hline SHproc & \#YYYYYYYYYY\# \\
\hline SHflux & \#YYYY\# \\
\hline PHhydr & \#YYYYYY\# \\
\hline PHderv & \#YYY\# \\
\hline PHproc & \#YYYYYYYYYY\# \\
\hline PHflux & \#YYYY\# \\
\hline Online & $\# \mathrm{~N} \#$ \\
\hline Wagmod & $\# \mathrm{~N} \#$ \\
\hline WaveOL & \#Y\# \\
\hline
\end{tabular}


Table 1.2. Model parameters and settings for the WAVE portion of the deterministic applications as set in model master definition wave file (.mdw). Specific input file names for grid, initial dates, runtimes, enclosure, depth, friction, dry points, winds, boundary conditions, sediment, morphology, and observations are excluded.

\begin{tabular}{|l|l|}
\hline \multicolumn{2}{|c|}{ Master definition wave input } \\
\hline Input name & Value \\
\hline SimMode & stationary \\
\hline DirConvention & nautical \\
\hline ObstacleFile & obstacle.obt \\
\hline WindSpeed & $0.0000000 \mathrm{e}+000$ \\
\hline WindDir & $0.0000000 \mathrm{e}+000$ \\
\hline WaterLevelCorrection & $0.0000000 \mathrm{e}+000$ \\
\hline Gravity & $9.8100004 \mathrm{e}+000$ \\
\hline WaterDensity & $1.0250000 \mathrm{e}+003$ \\
\hline NorthDir & $9.0000000 \mathrm{e}+001$ \\
\hline MinimumDepth & $5.0000001 \mathrm{e}-002$ \\
\hline GenModePhys & 3 \\
\hline Breaking & true \\
\hline BreakAlpha & $1.0000000 \mathrm{e}+000$ \\
\hline BreakGamma & $7.3000002 \mathrm{e}-001$ \\
\hline Triads & false \\
\hline TriadsAlpha & $1.0000000 \mathrm{e}-001$ \\
\hline TriadsBeta & $2.2000000 \mathrm{e}+000$ \\
\hline BedFriction & truenswap \\
\hline BedFricCoef & $6.7000002 \mathrm{e}-002$ \\
\hline Diffraction & false \\
\hline DiffracCoef & $2.0000000 \mathrm{e}-001$ \\
\hline DiffracSteps & 5 \\
\hline DiffracProp & true \\
\hline WindGrowth & true \\
\hline WhiteCapping & Komen \\
\hline Quadruplets & true \\
\hline Refraction & FreqShiftt \\
\hline
\end{tabular}


Table 1.2. Model parameters and settings for the WAVE portion of the deterministic applications as set in model master definition wave file (.mdw). Specific input file names for grid, initial dates, runtimes, enclosure, depth, friction, dry points, winds, boundary conditions, sediment, morphology, and observations are excluded.-Continued

\begin{tabular}{|c|c|}
\hline \multicolumn{2}{|c|}{ Master definition wave input } \\
\hline Input name & Value \\
\hline WaveForces & radiation stresses \\
\hline DirSpaceCDD & $5.0000000 \mathrm{e}-001$ \\
\hline FreqSpaceCSS & $5.0000000 \mathrm{e}-001$ \\
\hline RChHsTm01 & $2.0000000 \mathrm{e}-002$ \\
\hline RChMeanHs & $2.0000000 \mathrm{e}-002$ \\
\hline RChMeanTm01 & $2.0000000 \mathrm{e}-002$ \\
\hline PercWet & $9.8000000 \mathrm{e}+001$ \\
\hline MaxIter & 15 \\
\hline TestOutputLevel & 0 \\
\hline TraceCalls & false \\
\hline UseHotFile & false \\
\hline MapWriteInterval & 180 \\
\hline WriteCOM & true \\
\hline COMWriteInterval & 180 \\
\hline WriteTable & true \\
\hline WriteSpec1D & false \\
\hline WriteSpec2D & true \\
\hline \multicolumn{2}{|c|}{ Sample boundary settings } \\
\hline Name & Bound1 \\
\hline Definition & grid-coordinates \\
\hline StartCoordM & 0 \\
\hline EndCoordM & 0 \\
\hline StartCoordN & 0 \\
\hline EndCoordN & 39 \\
\hline SpectrumSpec & from file \\
\hline Spectrum & TPAR1.bnd \\
\hline
\end{tabular}


Table 1.2. Model parameters and settings for the WAVE portion of the deterministic applications as set in model master definition wave file (.mdw). Specific input file names for grid, initial dates, runtimes, enclosure, depth, friction, dry points, winds, boundary conditions, sediment, morphology, and observations are excluded.-Continued

\begin{tabular}{|c|c|}
\hline \multicolumn{2}{|c|}{ Master definition wave input } \\
\hline Input name & Value \\
\hline \multicolumn{2}{|c|}{ Outer and inner nested wave domain settings } \\
\hline FlowBedLevel & 1 \\
\hline FlowWaterLevel & 1 \\
\hline FlowVelocity & 1 \\
\hline FlowWind & 1 \\
\hline DirSpace & circle \\
\hline NDir & 72 \\
\hline StartDir & $0.0000000 \mathrm{e}+000$ \\
\hline EndDir & $0.0000000 \mathrm{e}+000$ \\
\hline FreqMin & $5.0000001 \mathrm{e}-002$ \\
\hline FreqMax & $1.0000000 \mathrm{e}+000$ \\
\hline NFreq & 24 \\
\hline Output & true \\
\hline \multicolumn{2}{|c|}{ Inner nested wave domain settings } \\
\hline NestedInDomain & 1 \\
\hline
\end{tabular}


Table 1.3. Model parameter and settings for the morphology portion of each deterministic application as set in model morphology file (.mor).

\begin{tabular}{|c|c|}
\hline \multicolumn{2}{|c|}{ Master Definition File Input } \\
\hline Input Name & Value \\
\hline EpsPar & False \\
\hline IopKCW & 1 \\
\hline $\mathrm{RDC}$ & 0.01 \\
\hline RDW & 0.02 \\
\hline MorFac & 0 \\
\hline MorStt & $3.6000000 \mathrm{e}+002$ \\
\hline Thresh & $5.0000001 \mathrm{e}-002$ \\
\hline MorUpd & false \\
\hline EqmBc & true \\
\hline SensIn & false \\
\hline AksFac & $1.0000000 \mathrm{e}+000$ \\
\hline RWave & $2.0000000 \mathrm{e}+000$ \\
\hline AlfaBs & $1.0000000 \mathrm{e}+000$ \\
\hline AlfaBn & $1.5000000 \mathrm{e}+000$ \\
\hline Sus & $1.0000000 \mathrm{e}+000$ \\
\hline Bed & $1.0000000 \mathrm{e}+000$ \\
\hline SusW & $0.0200000 \mathrm{e}+000$ \\
\hline BedW & $0.0200000 \mathrm{e}+000$ \\
\hline SedThr & $1.0000000 \mathrm{e}-001$ \\
\hline ThetSD & $0.2000000 \mathrm{e}+000$ \\
\hline HMaxTH & $1.5000000 \mathrm{e}+000$ \\
\hline FWfac & $1.0000000 \mathrm{e}+000$ \\
\hline Multi & -- \\
\hline NeuBcSand & true \\
\hline AverageAtEachOutputTime & true \\
\hline BedTranspDueToCurrentsAtZeta & true \\
\hline BedTranspDueToWavesAtZeta & true \\
\hline SuspTranspDueToWavesAtZeta & true \\
\hline
\end{tabular}


Table 1.3. Model parameter and settings for the morphology portion of each deterministic application as set in model morphology file (.mor).-Continued

\begin{tabular}{|c|c|}
\hline \multicolumn{2}{|c|}{ Master Definition File Input } \\
\hline Input Name & Value \\
\hline HidExp & true \\
\hline $\mathrm{Dm}$ & true \\
\hline Percentiles & 10506090 \\
\hline
\end{tabular}

Table 1.4. Model parameter and settings for the FLOW portion of the mormerge application as set in model master definition file (.mdf). Only parameters and settings unique to the mormerge application are given. Values not given are duplicated in table 1.1, above. Specific input file names for grids, initial dates, runtimes, enclosure, depth, friction, dry points, winds, boundary conditions, sediment, morphology, and observations were excluded.

\begin{tabular}{|c|c|}
\hline \multicolumn{2}{|c|}{ Master definition file input } \\
\hline Input name & Value \\
\hline Sub1 & $\# \quad \#$ \\
\hline Wnsvwp & $\# \mathrm{~N} \#$ \\
\hline Wndint & \#Y\# \\
\hline
\end{tabular}

Table 1.5. Model parameter and settings for the WAVE portion of the mormerge application as set in model master definition wave file (.mdw). Only parameters and settings unique to the mormerge application are given. Values not given are duplicated in table 1.2, above. Specific input file names for grid, initial dates, runtimes, enclosure, depth, friction, dry points, winds, boundary conditions, sediment, morphology, and observations were excluded.

\begin{tabular}{|l|l|}
\hline \multicolumn{2}{|c|}{ Master definition wave input } \\
\hline Input name & \multicolumn{1}{c|}{ Value } \\
\hline WindGrowth & false \\
\hline Quadruplets & false \\
\hline \multicolumn{2}{|c|}{ Offshore boundary settings } \\
\hline Name & Bound1 \\
\hline Definition & grid-coordinates \\
\hline StartCoordM & 0 \\
\hline EndCoordM & 253 \\
\hline StartCoordN & 0 \\
\hline EndCoordN & 0 \\
\hline SpectrumSpec & parametric \\
\hline
\end{tabular}


Table 1.5. Model parameter and settings for the WAVE portion of the mormerge application as set in model master definition wave file (.mdw). Only parameters and settings unique to the mormerge application are given. Values not given are duplicated in table 1.2, above. Specific input file names for grid, initial dates, runtimes, enclosure, depth, friction, dry points, winds, boundary conditions, sediment, morphology, and observations were excluded.-Continued

\begin{tabular}{|l|l|}
\hline \multicolumn{2}{|c|}{ Master definition wave input } \\
\hline \multicolumn{1}{|c|}{ Input name } & Value \\
\hline Spectrum & jonswap \\
\hline PeriodType & peak \\
\hline DirSpreadType & power \\
\hline PeakEnhancedFac & $3.3000000 \mathrm{e}+000$ \\
\hline GaussSpread & $9.9999998 \mathrm{e}-003$ \\
\hline WaveHeight & 0.57275 \\
\hline Period & 6.2007 \\
\hline Direction & 129.4898 \\
\hline DirSpreading & $4.0000000 \mathrm{e}+000$ \\
\hline \multicolumn{1}{|c|}{ Example lateral boundary settings } \\
\hline Name & Bound2 \\
\hline Definition & grid-coordinates \\
\hline StartCoordM & 253 \\
\hline EndCoordM & 253 \\
\hline StartCoordN & 1 \\
\hline EndCoordN & 2 \\
\hline SpectrumSpec & from file \\
\hline Spectrum & p1.spc \\
\hline \multicolumn{1}{|c|}{ Outer and inner nested wave domain settings } \\
\hline FlowWind & 0 \\
\hline DirSpace & sector \\
\hline NDir & 18 \\
\hline StartDir & domain settings \\
\hline EndDir & 1 \\
\hline NestedInDomain & \\
\hline
\end{tabular}


Table 1.6. Model parameter and settings for the morphology portion of the mormerge application as set in model morphology file (.mor). Only parameters and settings unique to the mormerge application are given. Values not given are duplicated in table 1.3.

\begin{tabular}{|l|l|}
\hline \multicolumn{2}{|c|}{ Master definition file input } \\
\hline \multicolumn{1}{|c|}{ Input name } & \multicolumn{1}{c|}{ Value } \\
\hline MorFac & 365 \\
\hline MorUpd & true \\
\hline Multi & true \\
\hline
\end{tabular}


욱 $\frac{\Phi}{\infty}$ 